\title{
Neurons, Astrocytes, and Oligodendrocytes of the Rat Cerebral Cortex Originate from Separate Progenitor Cells: An Ultrastructural Analysis of Clonally Related Cells
}

\author{
Marla B. Luskin, ${ }^{1,2}$ John G. Parnavelas, ${ }^{3}$ and James A. Barfield ${ }^{1,2}$ \\ 1Department of Anatomy and Cell Biology and ${ }^{2}$ Department of Pediatrics, Emory University School of Medicine, Atlanta, \\ Georgia 30322 and 'Department of Anatomy and Developmental Biology, University College London, London WC1E 6BT, \\ United Kingdom
}

The diverse array of neurons and glia in the mammalian cerebral cortex arises from proliferating cells of the ventricular zone that surrounds the lateral ventricles of the developing brain. A fundamental but unresolved question is whether the individual cells of the ventricular zone are committed to producing progeny of only one particular phenotype or whether they generate progeny of more than one phenotype. We have begun to address this question by asking if individual cells of the ventricular zone generate exclusively neurons or glia at the onset of cortical neurogenesis in the rat.

To assess the phenotypes of cells derived from a common progenitor cell, retroviral-mediated gene transfer was used to introduce the reporter gene, Escherichia coli $\beta$-galactosidase, into ventricular zone cells at embryonic day 15 or 16. We used histochemistry to reveal $\beta$-galactosidase-expressing cells in the mature rat cerebral cortex. Isolated clusters of $\beta$-galactosidase-expressing cells, presumably clones, were identified in serial sections. Since the histochemical reaction product is electron dense, each cell could be examined at the ultrastructural level and assigned definitively to one of the major classes of cells in the cerebral cortex on the basis of well-established morphological criteria. This approach overcomes the problems of cell type identification encountered with light microscopy, where it is not always possible to distinguish between different cell phenotypes.

We found that virtually all clones contained cells of exclusively one type: either all astrocytes, all oligodendro-

\footnotetext{
Received May 27, 1992; revised Aug. 31, 1992; accepted Nov. 10, 1992.

We are extremely grateful to Eileen Breding for photographic assistance, to Megan Maultsby and Eva Franke for technical assistance, and to Dr. W. Scott Clark for advice on statistical analysis. We also extend our appreciation to Drs. Joel Glover, Joshua Sanes, Carla Shatz, and Donald Wigston for helpful comments on the manuscript. M.B.L. was supported by a fellowship from the Alfred P. Sloan Foundation, a Biomedical Scholars Award from the Pew Charitable Trusts, and a Basil O'Connor Starter Scholar Research Award from the March of Dimes Birth Defects Foundation (5-FY90-798). Additional support was provided by a grant from NIH (NS28380), the University Research Committee of Emory University, and NATO to M.B.L and the MRC to J.G.P (Grant G9006412N).

Correspondence should be addressed to Dr. Marla B. Luskin, Department of Anatomy and Cell Biology, Emory University School of Medicine, Atlanta, GA 30322.
}

Copyright @ 1993 Society for Neuroscience $0270-6474 / 93 / 131730-21 \$ 05.00 / 0$ cytes, or all neurons. Furthermore, each particular cell type exhibited a different pattern and intensity of staining. The neuronal clones, with one exception, were composed of either all pyramidal cells (projection neurons), or all nonpyramidal cells (interneurons). The size and composition of neuronal clones did not seem related to their position in the cerebral cortex.

Collectively, our observations indicate that separate progenitor cells exist for pyramidal neurons, nonpyramidal neurons, astrocytes, and oligodendrocytes. The striking phenotypic homogeneity in the clones arising from individual progenitor cells suggests that by the onset of cortical neurogenesis, at least some lineage restrictions have already occurred among the precursor cell population. Thus, our results suggest that lineage may play a pivotal role in determining some of the functionally important phenotypic attributes of cells in the cerebral cortex.

IKey words: lineage, recombinant retrovirus, glia, pyramidal cells, nonpyramidal cells, cortical development, interneurons, phenotype, cell identity]

Many aspects of the development of the mammalian cerebral cortex have been elucidated by analyzing the patterns of generation and migration of cells destined for the telencephalon (for review, see McConnell, 1988, 1991). A general observation is that the early development of the cerebral cortex is strikingly similar in all species of mammals examined. The ventricular zone, a layer of seemingly homogeneous cells, surrounds the lateral ventricles and is the source of all neurons and glia in the cerebral cortex. Once generated, neurons migrate toward the pial surface and complete their differentiation in the cortical plate, the forerunner of the mature cerebral cortex. Both the generation and migration of neurons occur over an extended period. Neurons destined for the deep layers of the cortex are generated and then migrate away from the ventricular zone earlier than neurons destined for progressively more superficial layers. In many species, including the rat, neurogenesis occurs prenatally, although migration of cortical neurons may extend into the postnatal period. On the other hand, in the developing telencephalon the greatest production of astrocytes and oligodendrocytes occurs postnatally, after the production of neurons has ceased, although glial cells are also derived initially from progenitor cells of the ventricular zone. Even though much is known about the sequence of events underlying the development 
of the mammalian cerebral cortex, less is known about how cells of the cerebral cortex acquire their identity. Current hypotheses suggest that the determination of cell fate in the cerebral cortex involves a series of decisions restricting the potential of a progenitor cell or its offspring. The long-term goal of our study is to reveal how, when, and where these decisions are made.

To generate the many cell types that characterize the complex mature cerebral cortex, the developing nervous system must have the ability to regulate cellular production and differentiation. A number of mechanisms have been proposed to explain how cell diversity in the cerebral cortex arises (for review, see Levitt et al., 1981). Some authors have suggested that cells remain multipotential even after migrating away from the ventricular zone (for review, see Rakic, 1981). Multipotentiality has been construed as evidence that environmental factors, such as cell-cell interactions, control the fate of cells. However, recent reports have suggested that a cortical cell's identity may be specified even before it leaves the ventricular zone, implying a greater influence of inherited factors, such as cytoplasmic determinants, in dictating cell fate (Levitt et al., 1981, 1983; LeVine and Goldman, 1988; Luskin et al., 1988). To further our understanding about the contribution of inherited and environmental factors to the determination of cell fate, we have attempted to elucidate the lineage relationships of the different cell types in the cerebral cortex. A fundamental question is whether the cells of the ventricular zone are as homogeneous as their morphological similarity suggests (Sauer, 1935; Hinds and Ruffett, 1971) or whether they constitute a heterogeneous population such that some become committed to producing only neurons while others give rise exclusively to astrocytes or oligodendrocytes. We reasoned that the onset of neurogenesis may be a likely time for lineage restrictions to be manifested because not only is proliferation occurring, but more importantly, the first postmitotic cortical neurons are being generated.

Several recent studies (Luskin et al., 1988; Price and Thurlow, 1988; Walsh and Cepko, 1988) have focused on whether the lineages for neurons and glia diverge during development of the rodent cerebral cortex. These studies employed retrovirally mediated gene transfer to introduce a readily detectable marker, the gene for $\beta$-galactosidase from Escherichia coli, into progenitor cells of the ventricular zone at various times during embryonic development. One study (Luskin et al., 1988) has argued that by the onset of cortical neurogenesis, lineage restrictions do indeed exist, whereas other studies have suggested that the lineages for neuronal and non-neuronal cells are not yet distinct (Price and Thurlow, 1988; Walsh and Cepko, 1988) and that some progenitor cells may even remain multipotential throughout neurogenesis (Walsh and Cepko, 1988). A major drawback of the methodology in all of these studies, which may account for the conflicting conclusions, is that at the light microscopic level the determination of cell phenotype, based on the morphology of each $\beta$-galactosidase-positive cell, can be inconclusive. Here, to overcome problems of cell type identification at the light microscopic level, we have analyzed the phenotypes of all the $\beta$-galactosidase-positive progeny of an infected progenitor cell at the ultrastructural level. Using ultrastructural criteria, we show that discrete clusters of $\beta$-galactosidase-positive cells are composed of either all neurons, all astrocytes, or all oligodendrocytes, from which we infer that there are separate progenitor cells for the major cell types of the cerebral cortex.

Preliminary accounts of this work have appeared previously (Barfield et al., 1990; Parnavelas et al., 1991).

\section{Materials and Methods}

Production of retrovirus. Two different replication-defective recombinant retroviruses were used to analyze lineage relationships among cells in the cerebral cortex. The construction and production of the retroviruses have been described in detail elsewhere (Bonnerot et al., 1987; Price et al., 1987). Briefly, the recombinant retroviruses were constructed by replacing the viral genes gag, pol, and env of the Moloney murine leukemia virus, with the $E$. coli $\beta$-galactosidase gene, abbreviated $l a c Z$. We adhere to the convention of abbreviating the encoded gene product of lac $Z$ as lacZ. Most of the animals used in our studies received an injection of the BAG retrovirus vector (Price et al., 1987; ATTC CRL 1858 ). In the progeny of cells infected by the BAG retrovirus, the $\beta$-galactosidase gene product is localized predominantly in the cytoplasm. The other retroviral vector used, nls-lacZ (Nuclear Localizing Signal) (Bonnerot et al., 1987), targets the $\beta$-galactosidase gene product to the nucleus. Expression of $\beta$-galactosidase in the BAG vector construct is driven by the viral long terminal repeat sequence, and in the nls-lacZ vector, expression is controlled by the SV 40 early promotor.

The replication-defective recombinant retrovirus of both BAG and nls-lacZ was obtained by collecting and filtering the culture medium used to grow the virus-producing cells. The NLS recombinant retrovirus producer cell line was generously provided by Dr. Gary Nolan (MIT, Cambridge, MA). The BAG virus-producing cells purchased from ATTC were subcloned to generate a higher-titer-producing cell line. Titers of retrovirus, determined according to published procedures (Cepko, 1990), were in the range of $10^{4}$ colony-forming units $(\mathrm{cfu}) / \mathrm{ml}$ for nls-lacZ and $10^{5}$ to $10^{6} \mathrm{cfu} / \mathrm{ml}$ for BAG. In addition, a greater than 10 -fold increase in viral titers was obtained by concentrating the BAG virus, which proved unnecessary. Using a standard test, as described by Luskin et al. (1988), each lot of recombinant retrovirus used in our experiments was proven not to manufacture replication-competent virus.

Animals and surgical procedures. In these studies, female SpragueDawley rats obtained from our own colony were bred to obtain fetuses of known gestational ages. The day at which a plug was detected, signifying that insemination had occurred, was designated as embryonic day 0 (E0). By this convention, gestation usually lasts $22 \mathrm{~d}$.

Either the BAG or nls-lacZ retroviral lineage tracer, containing the reporter gene $E$. coli $\beta$-galactosidase, was injected into the cerebral ventricles of rat embryos. A direct injection into the ventricular zone is not feasible due to the small size and mobility of the embryo. Nonetheless, intraventricular injections give the injected retrovirus access to proliferating cells in the ventricular zone, and the progenitor cells that integrate the viral DNA subsequently pass it on to their progeny. Since we wanted to tag progenitor cells at the stage of development when cortical neurons are beginning to withdraw from the mitotic cycle, the retrovirus was injected on either E15 or E16, which is the onset of rat cortical neurogenesis (Raedler and Raedler, 1978). In order to inject embryos with retrovirus, pregnant rats were anesthetized with an intraperitoneal injection of chloral hydrate $(400 \mathrm{mg} / \mathrm{kg})$ prior to performing a laparotomy. Their uterine horns were exposed and a fiber optic light source was used to transilluminate each uterine swelling so that the orientation of the fetal head could be established without incising the uterus. Once the ventricles were visualized, the uterine membranes and fetal skull were penetrated with a glass micropipette attached to a pneumatic pump (World Precision Instruments Picopump). A solution (0.5-1.0 $\mu$ l) containing retrovirus $\left(10^{4}\right.$ to $10^{7}$ viral particles $\left./ \mathrm{ml}\right)$, polybrene $(0.05 \mathrm{mg} /$ $\mathrm{ml})$, and fast green dye $(0.05 \%)$ was pressure injected into the embryonic cerebral ventricles. The fast green dye was used to verify that the retrovirus was released into one of the lateral ventricles. When injections were complete, the abdominal incision was closed and the animal was placed under an infrared lamp until awake and active.

Histochemistry and tissue processing. Injected fetuses were born and allowed to survive until between 1 and 4 months of age, by which time the cytoarchitecture and the morphology of cells of the cerebral cortex are adult-like. Animals were deeply anesthetized with ether and perfused through the heart with $2 \%$ paraformaldehyde and $0.4 \%$ glutaraldehyde in $0.1 \mathrm{~m}$ phosphate buffer, $\mathrm{pH} 7.4$. Brains were removed immediately and the posterior halves of the cerebral hemispheres were serially sectioned with a Vibratome at $100 \mu \mathrm{m}$. To reveal lacZ-positive cells histochemically, free-floating sections were incubated overnight at room temperature with a mixture containing the substrate for $\beta$-galactosidase, 5 -bromo-4-chloro-3-indolyl- $\beta$-galactosidase (X-Gal), $1 \mathrm{mg} / \mathrm{ml}$ in phosphate-buffered saline, $\mathrm{pH} 7.3$, and $0.02 \%$ (w/v) sodium deoxycholate, $0.01 \%(\mathrm{w} / \mathrm{v}) \mathrm{NP}-40,4 \mathrm{~mm}$ potassium ferrocyanide, $4 \mathrm{~mm}$ potassium 
A



B

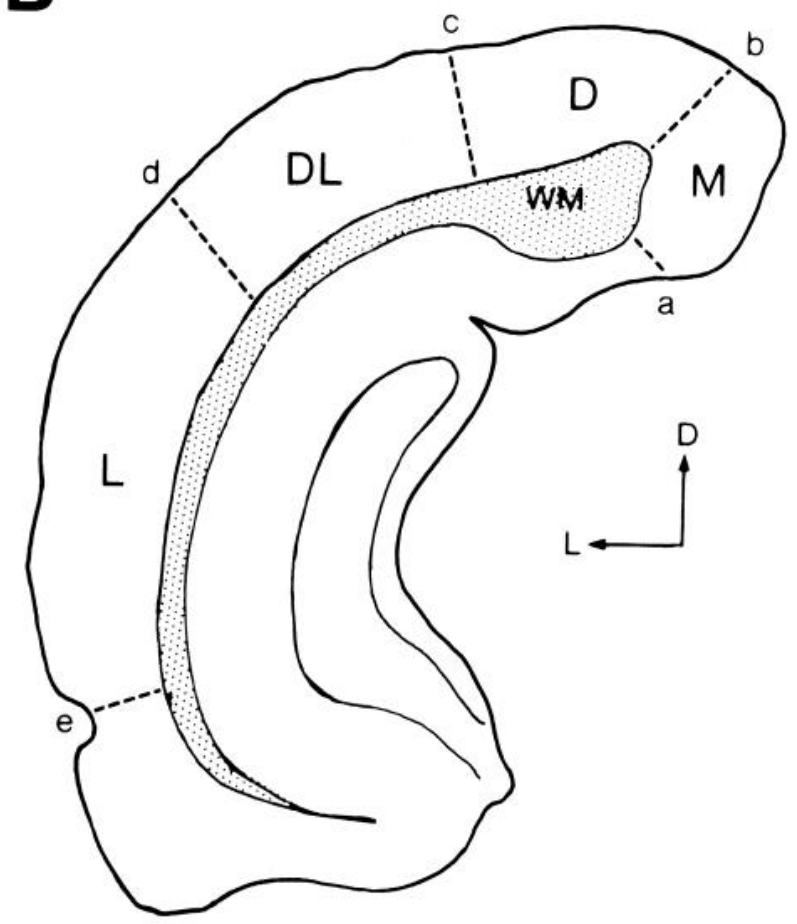

ferricyanide, and $2 \mathrm{~mm} \mathrm{MgCl}_{2}$ (procedure modified from Luskin et al., 1988).

Subsequently, sections were rinsed in $0.1 \mathrm{~m}$ phosphate buffer ( $\mathrm{pH} 7.4$ ), postfixed for 30 min with $1 \% \mathrm{OsO}_{4}$, stained with $1 \%$ uranyl acetate, dehydrated and flat-embedded in Araldite resin, and placed in a $60^{\circ} \mathrm{C}$ oven for 2-3 d. Following the identification of clones (see below), all of the cells belonging to selected clusters of lacZ-positive cells were excised from the sections, mounted on Araldite stubs, and thin sectioned. A minimum of 30 thin sections per cell were cut and examined with the electron microscope.

Location and identification of clones. Camera lucida drawings (final magnification, $31 \times$ ) were made of each section to document the positions of lacZ-positive cells. In addition, higher-magnification camera lucida drawings (final magnification, 125-312 $\times$ ) were made to describe the light microscopic appearance of each stained cell accurately. This often required reconstructing the cell from several planes of focus within the $100 \mu \mathrm{m}$ section, and as necessary between adjacent sections. Occasionally, a photomicrograph of a cell or group of cells was obtained to compare its appearance at the light microscopic level to its appearance at the ultrastructural level after thin sectioning.

We defined a clone as a cluster of closely spaced lacZ-positive cells separated from any other labeled cells by at least $500 \mu \mathrm{m}$ in the tangential plane, which is in the plane parallel to the overlying pial surface. This definition of a clone is based on an accepted inference that discrete groups of lacZ-positive cells are the progeny of single infected progenitor cell (Sanes et al., 1986). The Binomial Test of Proportions was used to determine the probability that homogeneous groups of cells occur by chance (Snedecor and Cochran, 1980).

Camera lucida drawings of the positions of lacZ-positive cells in sequential $100 \mu \mathrm{m}$ sections were superimposed to identify closely spaced clusters of lacZ-positive cells as illustrated in Figure $1 \mathrm{~A}$. Composite drawings, including the relative location of all cells occurring in successive sections, were generated from these superimposed maps. To determine which clusters met our criteria for a clone, we measured the tangential distance between a cluster of lacZ-positive cells and the nearest, presumably, unrelated lacZ-positive cell. To measure what is referred to as the tangential distance separating two lacZ-positive cells, we drew a line between the position of each cell and the point at which a tangent crossed the overlying pial surface. The measured tangential distance between the two cells was the distance between these two lines. This procedure intentionally ignored distances in the radial dimension

Figure 1. A, Method of determining clonal boundaries and distance separating clones and individual cells within clones. To identify clusters of lacZ-positive cells (black dots), camera lucida drawings (e.g., $b-d$ ) of consecutive $100 \mu \mathrm{m}$ Vibratome sections are superimposed (e.g., $a$ ) so that the relative location of lacZ-positive cells is maintained in the composite drawing. To determine the tangential distance between any two lacZ-positive cells, lines were formed perpendicularly between the position of any given cell and the point at which this line intersects the overlying pial surface, and then the distance between these two lines was measured as illustrated in $a$ (e.g., $x, y$, and $z$ ). Using this method, the distance separating the two outermost cells of each individual clone, referred to as the tangential dimension of a clone, could be determined (denoted by $z$ in $a$ ). Similarly, the maximum tangential distance between cells within a clone $(y)$ and the distance between a cluster of lacZ-positive cells to the nearest unrelated lacZ-positive cell more than $500 \mu \mathrm{m}$ away $(x)$ was determined. The brackets in $a$ demarcate multicell clones. The continuity of blood vessels from section to section (e.g., arrow in $c$ ) was used to better align drawings. $D$, dorsal; $L$; lateral; $P$, posterior; $C T X$, cortex; $W M$, white matter. $B$, A representative coronal section of the adult ( 3 months postnatal) cerebral cortex subdivided into several regions in order to indicate where clusters of lacZ-positive cells were found. In virtually all of the sections the cortex could be partitioned into a medial $(M)$, dorsal $(D)$, dorsolateral $(D L)$, and lateral $(L)$ region based on its macroscopic and microscopic features. Boundaries between regions, modified from Austin and Cepko (1990), are demarcated by broken lines. The medial region occupied a zone stretching from the apex of the cerebral cortex (line $b$ ) to the hippocampal formation (line $a$ ). The dorsal region extended to line $c$, roughly halfway between lines $b$ and $d ; d$ was placed approximately $45^{\circ}$ along the circumference of the cortex from the ventral midline position. The lateral region extends as far ventrally as the rhinal sulcus (line e). $W M$, white matter. 
of the cortex and assured us that no lacZ-positive cells were within 500 $\mu \mathrm{m}$ of any cell cluster considered to be a clone.

Because the number of cells per clone and clone diameter varied, the tangential distance between a cluster of lacZ-positive cells and an unrelated cell was determined by measuring the separation between the outermost cell of the cluster and the nearest unrelated lacZ-positive cell (see Fig. 1A). We also measured the distance separating the two outermost cells of each individual clone in the tangential plane, referred to as the tangential dimension of a clone, and the maximum tangential distance between any two cells in a clone (see Fig. $1 A$, Tables 1-3). The measurements reflect the depth of cells in the $100 \mu \mathrm{m}$ Vibratome sections to the nearest 5-10 $\mu \mathrm{m}$ (see Tables 1-3). However, in some instances, the points used to depict cell position in the drawings were not drawn to scale. Instead, the lacZ-positive cells were usually represented as larger than the actual cell itself (cf. Figs. $5 B, 6 A, 7 A, 8 A, 9 A, 10 A, 11 A$ ). Therefore, to correct for any possible measuring errors, higher-magnification camera lucida drawings were used to determine accurately distances between lacZ-positive cell somas for the selected clusters chosen for further study.

The laminar positions of lacZ-positive cells within clones were also documented. Laminar assignments were based upon the reported fraction each particular layer occupies in the mature rat cerebral cortex (Zilles, 1985). Layers $1-4$ occupy the upper half of the cortex, while layers 5 and 6 generally compose the lower half. Finally, the cortex was subdivided into medial, dorsal, dorsolateral, and lateral regions as described in Figure $1 B$ so that individual clones could be assigned to a general cortical region.

Ultrastructural identification of cell phenotypes. Well-established criteria were used to identify neuronal and glial cell phenotypes at the ultrastructural level (Jones and Powell, 1970; Peters et al., 1976; Colonnier, 1981; Parnavelas et al., 1983, 1989; Vaughan, 1984; Peters, 1985). LacZ-positive cells were then classified into one of four different cell types: astrocytes, oligodendrocytes, pyramidal neurons, or nonpyramidal neurons. The characteristic features of each cell type and the specific criteria used to classify lacZ-positive cells are given in Results.

\section{Results}

\section{Selection of lacZ-positive clusters for analysis of clonal composition}

The number and distribution of lacZ-positive cells in the adult cerebral cortex following injections of retrovirus at E15 or E16 varied considerably between brains, probably as a result of (1) differences in the amount of virus injected into the lateral ventricles and (2) the number of telencephalic progenitor cells infected. In several brains the lacZ-positive cells were far too numerous and widely scattered to allow for the recognition of a clone, and these brains were excluded from further study. Furthermore, isolated lacZ-positive cells were not analyzed even though they may represent single-cell clones.

The present study consists of an analysis of 27 clones obtained from six brains. Only one of these clones resulted from an injection of nls-lac $Z$ retrovirus (not illustrated) because the presence of the $\beta$-galactosidase histochemical reaction product was difficult to detect at the light microscopic level in nls-lacZexpressing cells compared to cells expressing the BAG retrovirus. The average distance between a clone and the nearest lacZ-positive cell was $750 \mu \mathrm{m}$ (see Tables 1-3); 18 of 27 were separated by $600 \mu \mathrm{m}$ or more from other labeled cells or clones, and three of these were more than $1 \mathrm{~mm}$ from any other lacZpositive cell. The nearest unrelated lacZ-positive cell to any given clone was either an isolated cell or part of another multicell clone.

\section{Appearance of lacZ-positive cells}

Appearance of lacZ-positive cells at the light microscopic level. The positions of the 192 lacZ-positive cells that made up the 27 clones selected for study were carefully mapped onto camera lucida drawings of the cerebral cortex, and the morphology of each cell was documented at the light microscopic level (e.g., Fig. $2 C$ ). There was substantial variability in the extent of the histochemical staining of the cell soma and processes of the lacZ-positive cells.

In a small proportion of the histochemically stained cells, the phenotype was readily apparent at the light microscopic level. In these cases a preliminary classification of cell phenotype was made, although electron microscopic confirmation was nearly always obtained. For example, the upper cell shown in Figure $2 \mathrm{~A}$ has the features of a pyramidal neuron, including a prominent apical dendrite, pyramidal shaped soma, and basal dendrites arising from the cell soma (only one is visible in the focal plane shown), whereas the two cells shown in Figure $2 B$, with substantial process staining, exhibit features associated with nonpyramidal ncurons. The relative simplicity of cell identification for some cells at the light microscopic level is even more apparent in Figure $2 C$, a camera lucida reconstruction of the same two cells, which fully depicts the dendritic branching pattern seen in different planes of focus. For some profusely stained lacZ-positive cells, the stained process was identified in adjacent sections, allowing for a more complete representation of cellular morphology. For neurons, the most frequently stained process was the dendrite while axons were seldom stained.

Despite the ease with which some lacZ-positive cells, particularly neurons, could be identified at the light microscopic level, the majority of lacZ-positive cells lacked well-delineated processes, and the determination of cell phenotype was difficult (e.g., Fig. $2 A$, lower cell), which is in agreement with other studies (Luskin et al., 1988; Price and Thurlow, 1988; Walsh and Cepko, 1988). This difficulty in determining cell phenotype at the light microscopic level was particularly serious for lacZpositive cells with relatively small somata that were expected to be astrocytes or oligodendrocytes such as those shown in Figure 2, $D$ and $E$, or small-diameter interneurons. It was not uncommon to find that one or a few members of a clone had stained processes, while in other cells of the same clone staining was restricted to the soma (e.g., Fig. 2A). Thus, despite the occasional lacZ-positive cell that was elaborately stained, the phenotype of most cells could not be determined conclusively by their light microscopic appearance alone.

Appearance of lacZ-positive cells at the ultrastructural level. At the electron microscopic level, with few exceptions, lacZpositive cells were readily distinguished from unlabeled cells by their conspicuous histochemical reaction product (see Fig. $3 A$ ). For example, Figure $3 A$ shows a row of three cells in the rat cerebral cortex, the middle being lacZ positive, as indicated by an increased overall density and an extension of reaction product into its proximal processes. The subcellular localization of the histochemical reaction product is shown in a higher-magnification electron micrograph (Fig. $3 B$ ). This subcellular localization is predominantly associated with the nuclear membrane and endoplasmic reticulum. Depending on the cell type, the reaction product may also be associated with nucleoplasm, mitochondria and the Golgi apparatus. We found that the phenotype of lacZ-positive cells could be ascertained readily by examining their fine structure. However, classification was not accomplished for 14 lacZ-positive cells (see Tables 1,2) because they were lost during electron microscopic processing. Fortunately, each of these cells had a light microscopic appearance similar to its presumed sibling that was extremely informative as to its phenotype.

The determination of cell phenotype was seldom impeded by 
Figure 2. Examples of the light microscopic appearance of lacZ-positive cells in the adult rat cerebral cortex resulting from an intraventricular injection of retrovirus at E15 $(A)$ or E16 $(B-E) . A, B, D$, and $E$ are photomicrographs of cells in 100- $\mu$ m-thick Vibratome sections. Note that in some lacZpositive cells the staining is restricted to the cell soma, whereas in others there is extensive process staining, assisting the identification of cell type. $A$, The upper cell has a pyramidal neuron morphology with apical and basal dendrites, but the phenotype of the lower cell is ambiguous because it lacks distinctive process staining. Upon examination at the ultrastructural level, this cell's neuronal identity was evident (not shown). $B$, Two lacZ-positive cells that exhibit features of nonpyramidal neurons. The camera lucida drawing in $C$, which was obtained by connecting processes in different planes of focus, depicts the full extent of the elaborate process staining of the two cells shown in $B$. $D$, The pattern of histochemical staining at the light microscopic level that was most commonly associated with astrocytes. This cell is one of the 17 astrocytes shown at the ultrastructural level in Figure 5. E, An array of four lacZ-positive cells (arrows) identified at the ultrastructural level as oligodendrocytes. The cells shown contribute to the clone illustrated in Figure 6 . The lack of process staining often exhibited by lacZ-positive glial cells frequently impedes their phenotypic identity at the light microscopic level. Scale bars: $A, 25 \mu \mathrm{m} ; B$ and $C, 100 \mu \mathrm{m} ; D$ and $E, 20 \mu \mathrm{m}$.
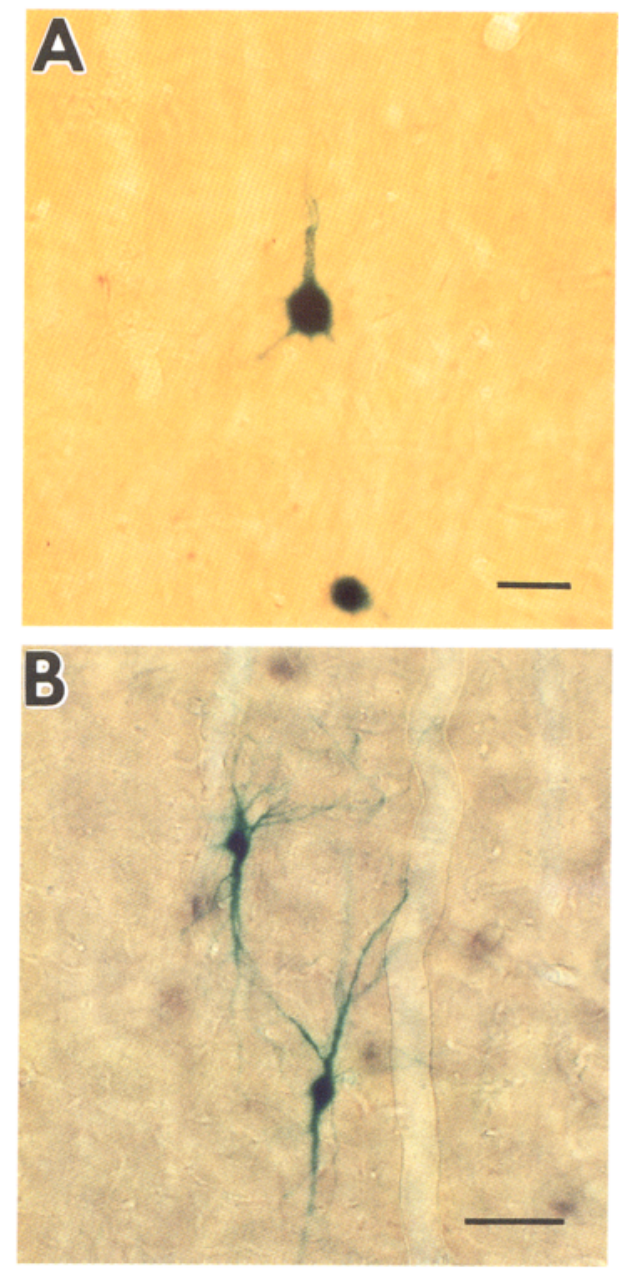

E16-P126


the presence of the $\beta$-galactosidase histochemical reaction product. There was little or no diffusion of the reaction product out of lacZ-positive cells, and thus, synapses contacting neuronal cell bodies were not obscured (see Fig. $3 B$ ). The clear visibility of the synapses was advantageous because the type of synapse(s) associated with lacZ-positive neuronal cell bodies was used to reliably determine their phenotypes (Colonnier, 1981; Peters, 1985). The patterns of staining associated with each cell type and the specific criteria for classifying cells are given below.

\section{Discrete clones of lacZ-positive cells with glial characteristics}

When comparing the phenotype of cells composing individual clones, we found that, with only two exceptions, all of the clones examined at the electron microscopic level contained cells of a single major class (see Tables 1-3). Half of the clones were composed of astrocytes or oligodendrocytes, but never a mixture of these two types of glia, and the remaining clones contained exclusively neurons. At the light microscopic level many lacZpositive glial cells had small, round cell bodies $(5-12 \mu \mathrm{m})$ with only a few, short, stained processes (see Fig. $2 D, E$ ); however, the ultrastructural appearance of lacZ-positive glia enabled us to distinguish readily between astrocytes and oligodendrocytes (Peters et al., 1976; Parnavelas et al., 1983; Vaughan, 1984). None of the cells classified as astrocytes or oligodendrocytes formed synapses.

Clones composed of astrocytes. Astrocytes can be distinguished from other cell types on the basis of a number of features. The most characteristic feature is the presence of glial 

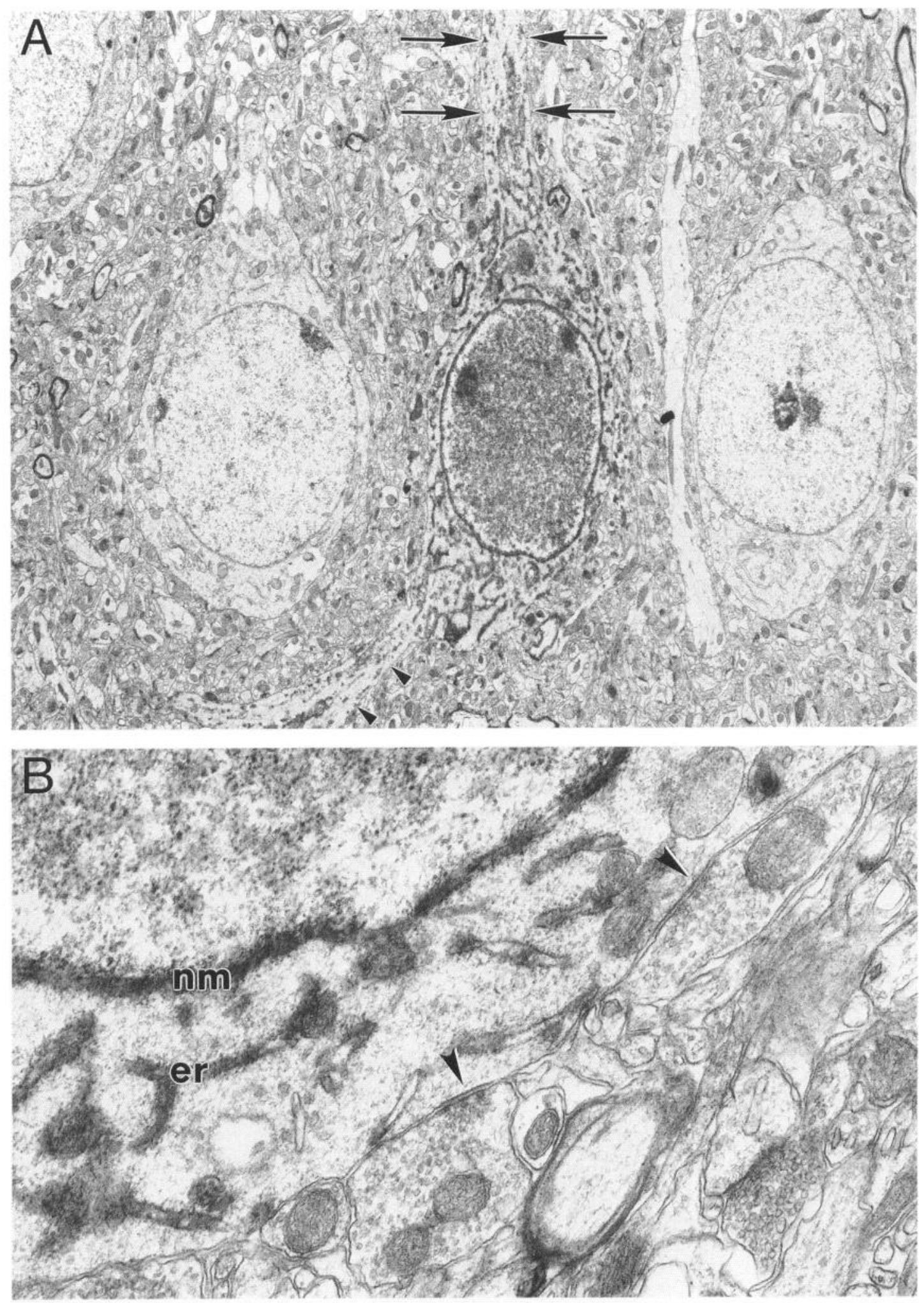

Figure 3. Electron micrographs demonstrating the prominent features of histochemically stained lacZ-positive cells in the rat cerebral cortex. $A$, An example of a lacZ-positive pyramidal neuron (center), flanked by two unstained pyramidal neurons in the mature cerebral cortex [postnatal day 83 (P83)], resulting from an injection of retrovirus at E16. Note that this lacZ-positive neuron is easily distinguished from the adjacent unstained neurons due to the conspicuous histochemical staining of its nucleus and cytoplasm. The identification of lacZ-positive cells is commonly facilitated by the extension of reaction product into proximal processes, particularly noticeable in the apical dendrite (arrows) and the laterally directed basal dendrite (arrowheads). The light microscopic appearance of this neuron is shown in Figure $7 B$ (cell c). $B$, High-magnification electron micrograph of another lacZ-positive neuron, showing the intracellular distribution of reaction product, which is a dense precipitate predominantly associated with the nuclear membrane $(\mathrm{nm})$ and granular endoplasmic reticulum $(\mathrm{er})$. Note that the fine structure of the axon terminals forming synapses (arrowheads) with the soma of the stained cell is not obscured. The light microscopic appearance of this neuron is shown in Figure $7 B$ (cell e). Magnification: $A, 5000 \times ; B, 38,000 \times$. 



Figure 4. Electron micrographs of representative lacZ-positive astrocytes and oligodendrocytes. Each occurs in a separate cluster of clonally related cells in the adult cerebral cortex resulting from an intraventricular injection of retrovirus at E15 $(B)$ or E16 $(A$ and $C)$. At the light microscopic level, it is not always possible to distinguish between astrocytes and oligodendrocytes, but at the ultrastructural level the differences can be readily appreciated. $A$ and $B$, In these two cells, as in other lacZ-positive astrocytes, the histochemical staining has a punctate appearance and encircles the nucleus (e.g., row of arrowheads in $A$ and $B$ ). The cytoplasm of both cells is electron lucent and organelle poor, which is typical of astrocytes in aldehyde-fixed tissue. In favorable sections, collections of glial filaments are discernible (e.g., arrow in $A$ ). The cell illustrated in $A$ was one of 32 lacZ-positive astrocytes composing a clone situated in the gray matter, whereas the cell in $B$, which is surrounded by profiles of myelinated axons, was one of 12 immature clonally related astrocytes located in the white matter. Note that the cells are adjacent to blood vessels $(b v)$, where astrocytes are frequently located. The electron micrograph in $C$ shows an example of a lacZ-positive oligodendrocyte. Both the unstained cell $(b)$ and the lacZ-positive cell (c) exhibit features associated with oligodendrocytes: electron-dense nuclei with pronounced aggregates of heterochromatin. Notice that these characteristic features of oligodendrocytes are apparent in cell $c$ despite the pronounced histochemical staining of its nucleus and cytoplasm. The unstained cell on the left $(a)$ is a neuron. Magnification: $A$ and $B$, $10,300 \times ; C, 11,300 \times$

filaments (Fig. 4A) in a typically electron-lucent cytoplasm (Skoff, 1980; Vaughan, 1984), although these filaments are lacking from the cytoplasm of immature astrocytes. Immature astrocytes typically contain a number of wide cisterns of granular endoplasmic reticulum (Parnavelas et al., 1983). Another feature specific to astrocytes is an irregular cytoplasmic outline that weaves between other cells and processes in the tissue. Furthermore, many astrocytes are located adjacent to blood vessels (Fig. $4 B$ ) and have processes that form the glial limitans at the pial surface (Peters et al., 1976).

For a lacZ-positive cell to be classified as an astrocyte, it must exhibit one or more of the astrocyte-specific ultrastructural features described. Virtually all of the cells judged to be astrocytes had an electron-lucent cytoplasm and $85 \%$ also showed filamentous arrays. In addition, many of the lacZ-positive cells scored as astrocytes were located adjacent to blood vessels (see Fig. $4 A, B)$ and had processes extending from their soma that insinuated between other profiles and cells in the tissue. The most distinctive aspect of the histochemical staining of lacZpositive astrocytes was the beaded distribution of reaction product along the nuclear membrane (Figs. $4 A, B$, arrowheads; $5 D$ $G$, small arrows). The $\beta$-galactosidase histochemical reaction product in the cytoplasm of these cells was sparse because they typically contained only a few organelles.

Discrete clusters of lacZ-positive astrocytes in the cerebral cortex were encountered in both the white and the gray matter, and some astrocyte clones extended into both zones (see Table 1). For example, Figure $4 A$ shows a representative lacZ-positive astrocyte from a clone containing 32 cells confined to the gray matter, whereas Figure $4 B$ shows a stained immature astrocyte from a 12-cell clone in the white matter, as indicated by the surrounding myelinated axons. The range of cells in the astrocyte clones examined was $2-32$ cells per clone. In general, the spatial dimension of astrocyte clones was proportional to the number 
A

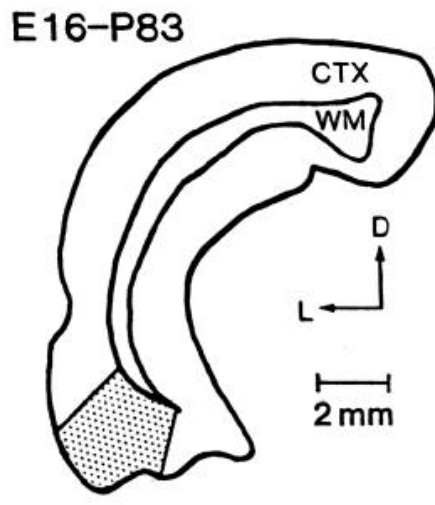

$C_{t}$

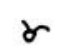

6

q

$\not$

d

or

*<smiles>C[Hg]</smiles>

b.
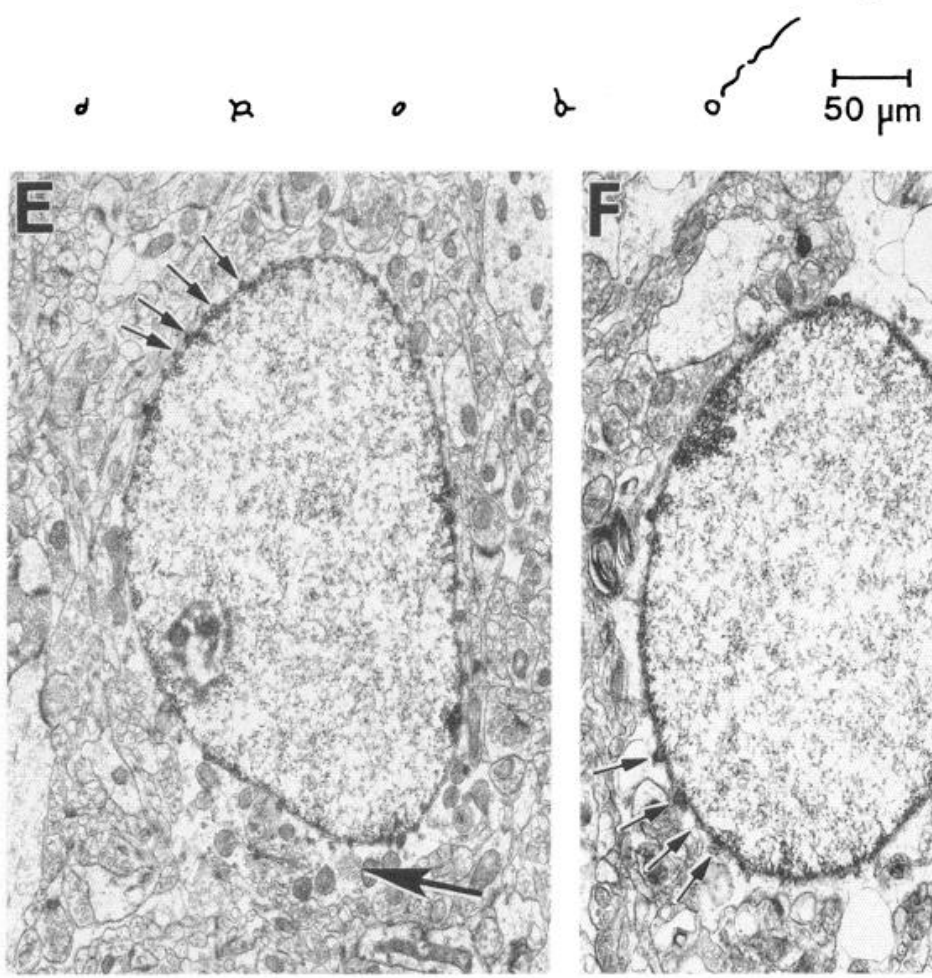
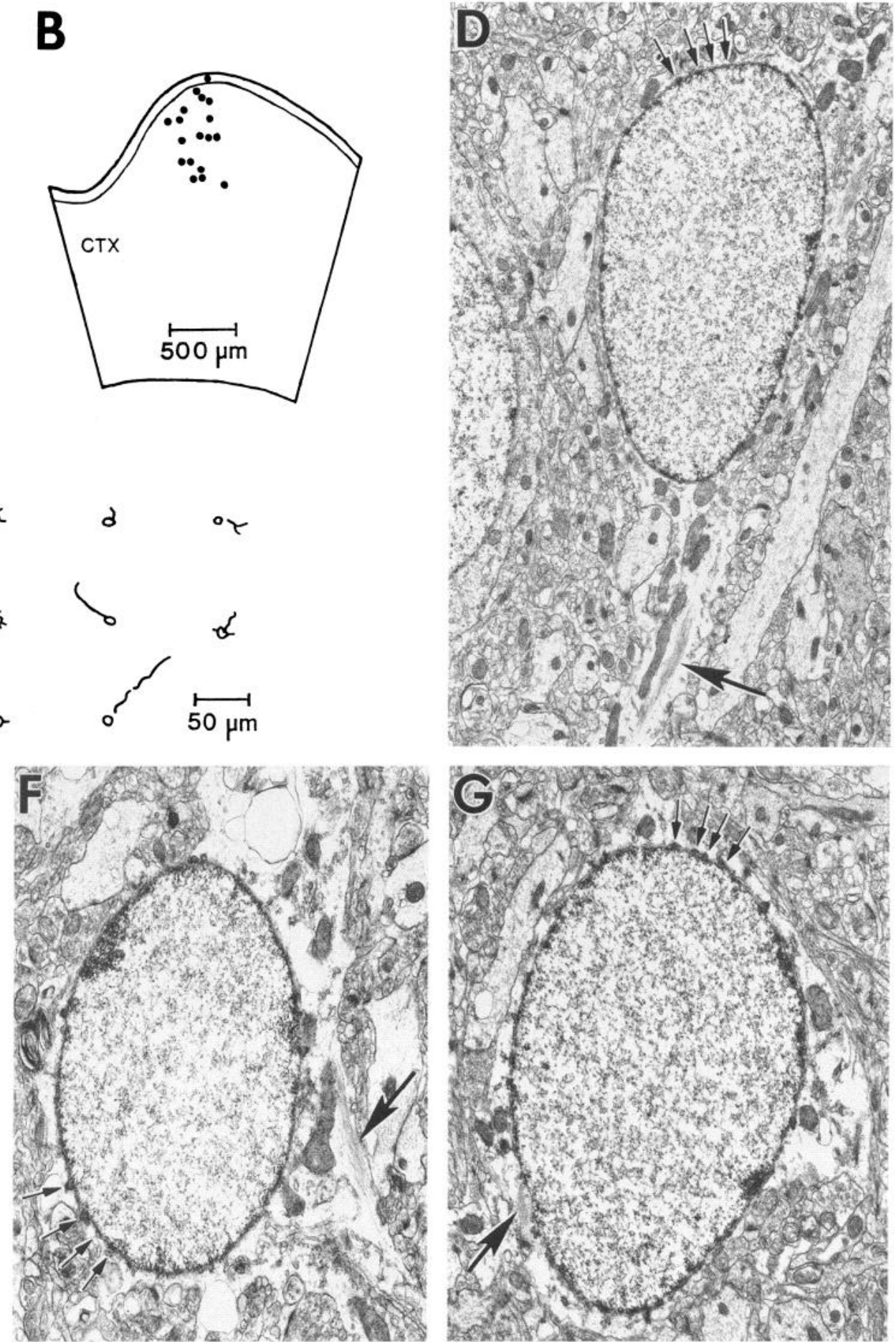

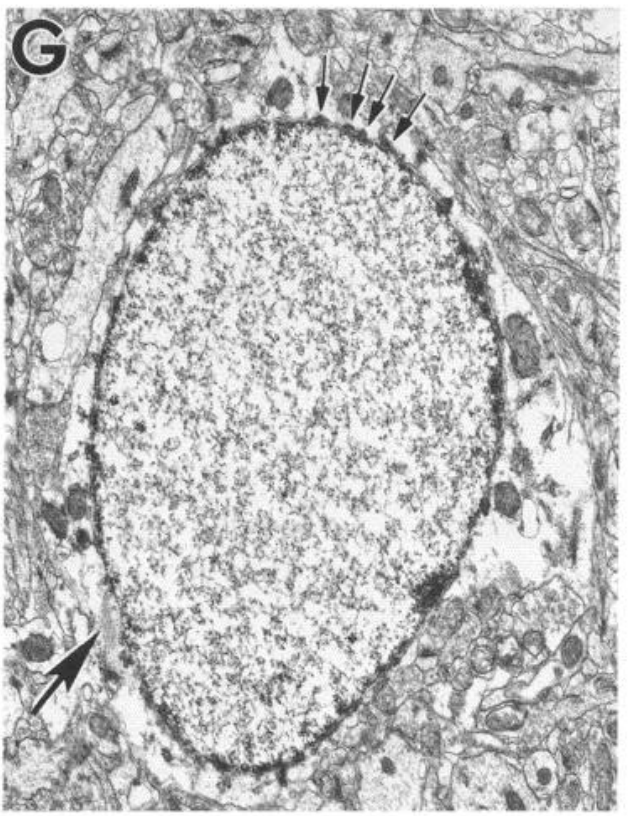

Figure 5. Reconstruction of a clone containing exclusively astrocytes and examples of the morphology of its constituent cells at the light and electron microscopic level from a rat brain injected with retrovirus at E16 and perfused at P83. $A$ shows the position of the clone in the entorhinal cortex. $B$ shows the spatial relationships between cells in the clone obtained by superimposing 11 serial $100 \mu \mathrm{m}$ sections. The clone extended 450 $\mu \mathrm{m}$ in its maximal lateral extent. The light microscopic morphology of each of the 17 cells composing the clone is illustrated in the camera lucida tracings shown in $C$. They exhibit a simple staining pattern that does not conclusively reveal their cell phenotype. However, at the ultrastructural level, every cell had characteristics of astrocytes as shown by the four cells illustrated $(D-G)$. The large arrows point to the collection of glial filaments present in each cell, viewed longitudinally $(D, F, G)$ or in cross section $(E)$, in the midst of an electron-lucent cytoplasm. Note the beaded distribution of the $\beta$-galactosidase histochemical reaction product around the nuclei (small arrows in $D-G$ ). $C T X$, cortex; $D$, dorsal; $L$, lateral; $W M$, white matter. Magnification: $D, 5500 \times ; E-G, 9000 \times$.

of cells in the clone (Table 1). Although cells within astrocyte clones were occasionally separated by relatively large distances $(>100 \mu \mathrm{m})$, the majority of cells within these clones were considerably more closely spaced $(<50 \mu \mathrm{m})$.
Figure 5 shows an example of one of the eight astrocyte clones reconstructed in this study. The clone was situated in the gray matter of the entorhinal cortex, and contained 17 cells, all of which had a very simple morphology at the light microscopic 
Table 1. Characteristics of individual glial clones

\begin{tabular}{|c|c|c|c|c|c|c|}
\hline $\begin{array}{l}\text { Age at } \\
\text { injection- } \\
\text { age at } \\
\text { perfusion }\end{array}$ & Phenotype of cells & $\begin{array}{l}\text { Number } \\
\text { of cells } \\
\text { per clone }\end{array}$ & $\begin{array}{l}\text { Location } \\
\text { (GM/WM) }\end{array}$ & $\begin{array}{l}\text { Tangential } \\
\text { dimensions } \\
\text { of clone }\end{array}$ & $\begin{array}{l}\text { Maximum } \\
\text { tangential } \\
\text { distance } \\
\text { between } \\
\text { cells in } \\
\text { clone }\end{array}$ & $\begin{array}{l}\text { Nearest } \\
\text { unre- } \\
\text { lated } \\
\text { lacZ(+) } \\
\text { cell }\end{array}$ \\
\hline E15-P64 & Astrocytes & 7 & GM/WM & $200 \times 200 \mu \mathrm{m}$ & $50 \mu \mathrm{m}$ & $600 \mu \mathrm{m}$ \\
\hline E15-P64 & $\begin{array}{l}\text { Astrocytes } \\
\text { (immature) }\end{array}$ & $11 / 12^{a}$ & WM & $200 \times 500 \mu \mathrm{m}$ & $300 \mu \mathrm{m}$ & $850 \mu \mathrm{m}$ \\
\hline E16-P83 & Astrocytes & 17 & GM & $450 \times 1100 \mu \mathrm{m}$ & $400 \mu \mathrm{m}$ & $1000 \mu \mathrm{m}$ \\
\hline E16-P83 & Astrocytes & 4 & GM & $50 \times 200 \mu \mathrm{m}$ & $100 \mu \mathrm{m}$ & $500 \mu \mathrm{m}$ \\
\hline E16-P83 & Astrocytes & $\approx 9$ & GM & $150 \times 100 \mu \mathrm{m}$ & $50 \mu \mathrm{m}$ & $500 \mu \mathrm{m}$ \\
\hline E16-P83 & Astrocytes & 32 & GM & $300 \times 200 \mu \mathrm{m}$ & $100 \mu \mathrm{m}$ & $2500 \mu \mathrm{m}$ \\
\hline E16-P88 & Astrocytes & 2 & GM & $30 \times 35 \mu \mathrm{m}$ & $55 \mu \mathrm{m}$ & $900 \mu \mathrm{m}$ \\
\hline E15-P24 & Astrocytes & $5 / 8^{a}$ & GM & $400 \times 200 \mu \mathrm{m}$ & $400 \mu \mathrm{m}$ & $600 \mu \mathrm{m}$ \\
\hline E16-P83 & Oligodendrocytes & $6 / 9^{a}$ & GM & $200 \times 100 \mu \mathrm{m}$ & $50 \mu \mathrm{m}$ & $600 \mu \mathrm{m}$ \\
\hline
\end{tabular}

E, embryonic day; $\mathrm{P}$, postnatal day; GM, gray matter; WM, white matter.

${ }^{a}$ Numerator represents number of cells identified by electron microscopy; denominator represents the total number of cells in the clone.

level. They exhibited short, sometimes wavy processes, extending from a small, often faintly labeled cell body (see Figs. $2 D$, $5 C$ ). This pattern of staining was not sufficient to identify these cells as astrocytes, but at the ultrastructural level all the cells displayed astrocyte-specific features (Fig. $5 D-G$ ). Each cell in the clone had glial filaments that could be seen in both longitudinal and cross sections, and each had an oval nucleus ringed by a punctate, beaded distribution of histochemical reaction product. Unlike the astrocytes shown in Figure 4, $A$ and $B$, none of the cells in this clone were located adjacent to blood vessels. A prominent feature of this clone, and many others, was the extraordinary resemblance among its cells.

Clones composed of oligodendrocytes. Figure $4 C$ allows for a comparison between a cell identified as a lacZ-positive oligodendrocyte and a cell identified as a lacZ-negative oligodendrocyte. Oligodendrocytes are usually readily detectable because they often show darker nuclei and cytoplasm than other cell types in the cerebral cortex and often contain small stacks of short cisterns of granular endoplasmic reticulum (Peters et al., 1976; Parnavelas et al., 1983; Vaughan, 1984). The minimum criteria we set for a lacZ-positive cell to be considered an oligodendrocyte was an overall dark appearance and the presence of dense clumps of heterochromatin in the nucleus. Although in the majority of lacZ-positive cells classified as oligodendrocytes, other features typical of oligodendrocytes were detectable (Peters et al., 1976; Vaughan, 1984), the presence of reaction product in the lacZ-positive oligodendrocytes occasionally rendered their cytoplasmic organelles difficult to resolve (see Fig. $4 C$, cell c). However, the heavy staining of oligodendrocytes ultimately served to facilitate our identification of these cells upon inspection of electron micrographs.

Only one pure oligodendrocyte clone was encountered. It was located in the gray matter of the hippocampus and contained nine cells in a compact configuration (Fig. 6A). At the light microscopic level, the cells were characterized by small cell bodies and short, branched processes (Fig. 6B). At the ultrastructural level, the nucleus and cytoplasm of every cell were darkly stained and the nuclei contained clumps of heterochromatin (Fig. $6 \mathrm{C}$ ). The two lacZ-positive oligodendrocytes illustrated in Figure $6 C$ sit juxtaposed to one another, suggesting that they arose by the division of oligodendrocyte progenitor cells that divided in situ (after migrating away from the ventricular zone). In addition to the one pure oligodendrocyte clone, one mixed clone containing 17 oligodendrocytes and a single neuron was also found and will be discussed below. Furthermore, our preliminary findings resulting from the injection of retroviral lineage tracers into the rat neonatal subventricular zone (after neurogenesis has ceased) have revealed homogeneous cloncs of astrocytes and oligodendrocytes, and no heterogeneous glial clones have been encountered (McDermott et al., 1991).

\section{Discrete clones of lacZ-positive cells with neuronal characteristics}

In the neuronal clones, the $\beta$-galactosidase histochemical staining at the light microscopic level revealed a range of morphological configurations, as exemplified by the neuronal clone depicted in Figure 7. Despite the ease with which some cells could be identified as neurons (e.g., Fig. 7C), the majority of lacZpositive cells in these clones required ultrastructural analysis for a conclusive determination of their phenotype. For example, cell $g$ in Figure $7 B$ could not be classified on the basis of its light microscopic appearance alone because of its rudimentary dendritic staining. However, when examined at the ultrastructural level, the cell displayed features consistent with a ncuronal identity (Fig. $7 E$ ), and it resembled other neurons easily recognizable as such at the light microscopic level [e.g., the lacZ-positive neuron shown in Fig. $7 D$ (cell $\mathrm{f}$ in Fig. $7 B$ )]. Thus, as was the case for glia, an ultrastructural analysis was essential to definitively establish neuronal identity as well as the subtypes of the lacZ-positive neurons contributing to clones (see below).

The five-cell neuronal clone illustrated in Figure 8 also shows that there can be considerable variability in the process staining between cells in a clone. Despite this variability, the distribution and density of reaction product at the ultrastructural level were remarkably similar for all five cells. Only the ultrastructural appearance of cell $b$ is shown because it had the least discernible phenotype at the light microscopic level (Fig. 8B). At the ultrastructural level it possesses the features of a nonpyramidal cell, including a mixture of symmetrical and asymmetrical synapses, 

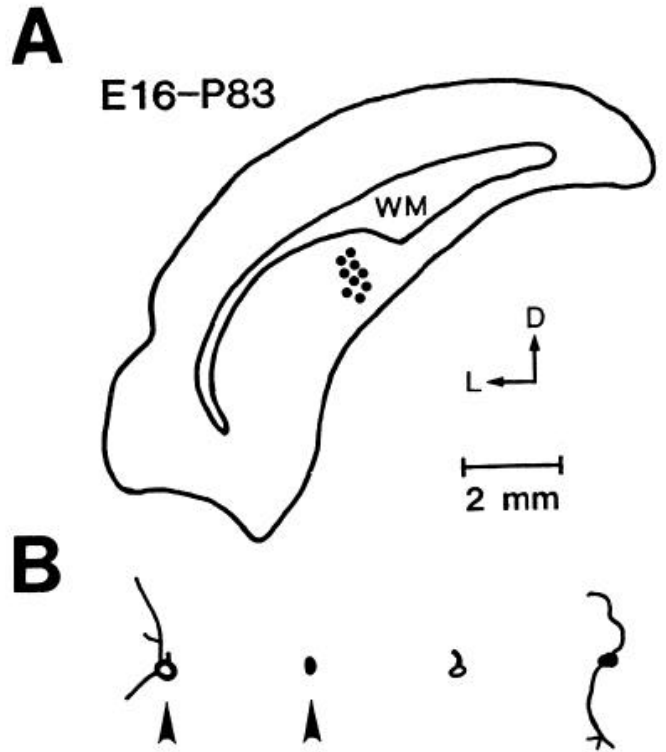

子
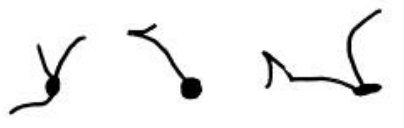
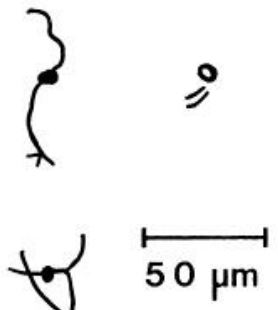

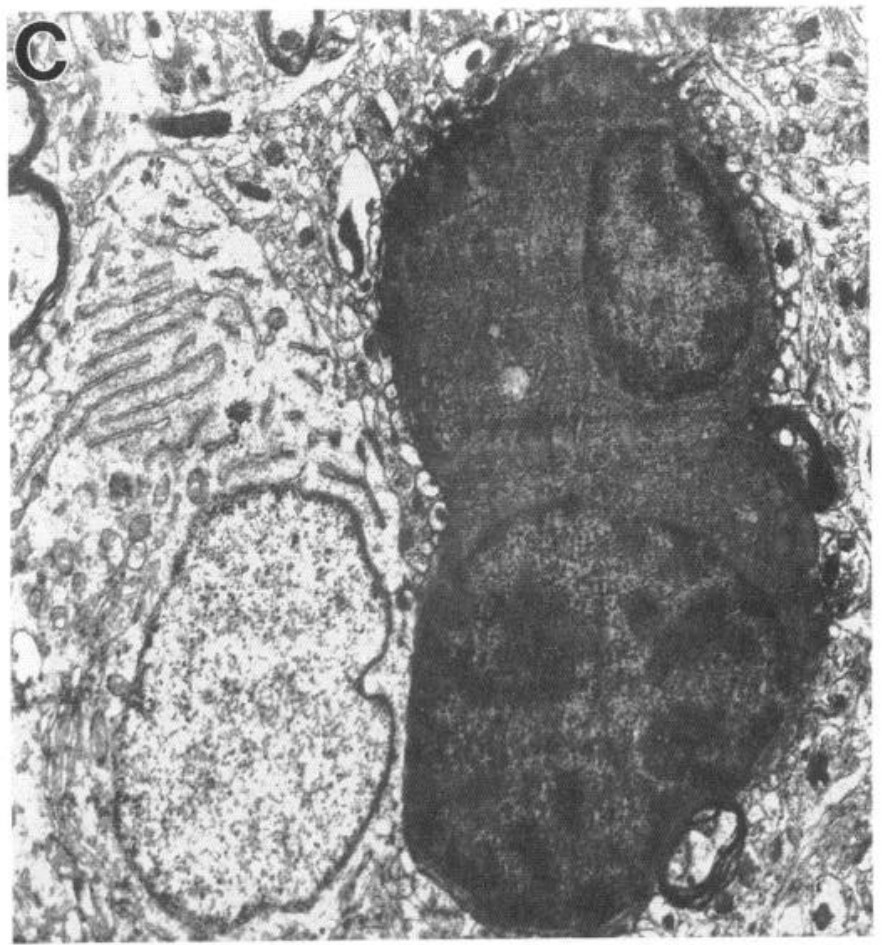

Figure 6. Reconstruction of a clone containing exclusively oligodendrocytes and examples of the morphology of its constituent cells at the light and electron microscopic level from a rat brain that received an intraventricular injection of retrovirus at E16 and perfused at P83. $A$ shows the position of the clone in the brain and the distribution of the cluster of nine lacZ-positive cells (black dots). The clone was reconstructed by superimposing two serial $100 \mu \mathrm{m}$ sections. The camera lucida tracings in $B$ show the light microscopic morphology of each cell. Some cells bear processes, similar to those of oligodendrocytes, whereas the majority of cells cannot be classified at the light microscopic level because they lack sufficient process staining. The arrowheads designate the two cells illustrated by the electron micrograph in $C$. Though they are heavily stained throughout their nucleus and cytoplasm, the dense clumps of heterochromatin, combined with other morphological features, indicate that they are oligodendrocytes, whereas the cell on the left is an unstained neuron. The close apposition of the two lacZ-positive oligodendrocytes suggests they are derived from the same progenitor cell. $W M$, white matter; $D$, dorsal; $L$, lateral. Magnification $(C), 3100 \times$.

and shared these features with the other cells belonging to the clone (not shown).

The neuronal clones contained between two and nine cells. Four of the seven clones containing only two or three neurons were restricted to a single layer of the cerebral cortex (layer 4), and in only one case did a clone of this size span three layers (Table 2). On the other hand, clones containing between four and nine neurons were usually distributed over three or more cortical layers and often the same clone contained cells in both the infragranular and supragranular layers.

To determine if there were any regional differences in the number of cells per clone or in the dimensions of clones, we partitioned the cortex into medial, dorsal, dorsolateral, and lateral divisions as shown in Figure $1 B$. No striking regional differences in the dimensions of neuronal clones were observed (Table 2). Furthermore, except for the lateral division, where the mean number of cells per clone was fewer (2.6), the mean number of cells per clone was comparable in the different divisions (medial, 4.5; dorsal, 5.25; dorsolateral, 5.25). The lower number of cells per clone in the lateral division can be partially explained by the observation that five of these six clones were composed of exclusively nonpyramidal neurons, which contained fewer cells on average (mean, 3.0 cells) than pyramidal cell clones (mean, 5.6 cells).

In order to investigate the lineage relationships between subtypes of neurons, the cells within neuronal clones were further classified as either pyramidal or nonpyramidal neurons on the basis of differences in morphology, ultrastructure, and, foremost, the type of axosomatic synapses they receive (Jones and Powell, 1970; Parnavelas et al., 1977; Colonnier, 1981; Peters, 1985). On average, in the mammalian cerebral cortex, pyramidal neurons have a larger cell soma diameter than nonpyramidal neurons (Peters, 1985). However, because the ranges of cell body diameters overlap (pyramidal neurons, 10-25 $\mu \mathrm{m}$; nonpyramidal neurons, $8-20 \mu \mathrm{m}$ ), cell soma diameter cannot be used as a decisive criterion to determine cell phenotype. Rather, the most definitive way of distinguishing pyramidal cells from nonpyramidal cells, and the one used here, is by the type of synapses they receive on their cell bodies. Pyramidal neurons receive exclusively symmetrical (Gray's type II, presumptive inhibitory) axosomatic synapses, whereas nonpyramidal neurons receive both symmetrical and asymmetrical (Gray's type I, presumptive excitatory) axosomatic synapses.

In an earlier study (Parnavelas et al., 1991), we concluded from the homogeneity of neuronal clones that pyramidal and nonpyramidal cells arise from different progenitor cells. The same pool of neuronal clones considered previously (including one additional clone) have been documented more thoroughly so that the tangential dimensions of a clone, maximum tangential distance between cells in a clone, nearest unrelated lacZpositive cells, and laminar position of cells in clones could be compared (see Tables 2, 3).

Interestingly, the neuronal clones arising from E15 and E16 injections pooled for analysis do in fact show some differences. 
A

E15-P64



B
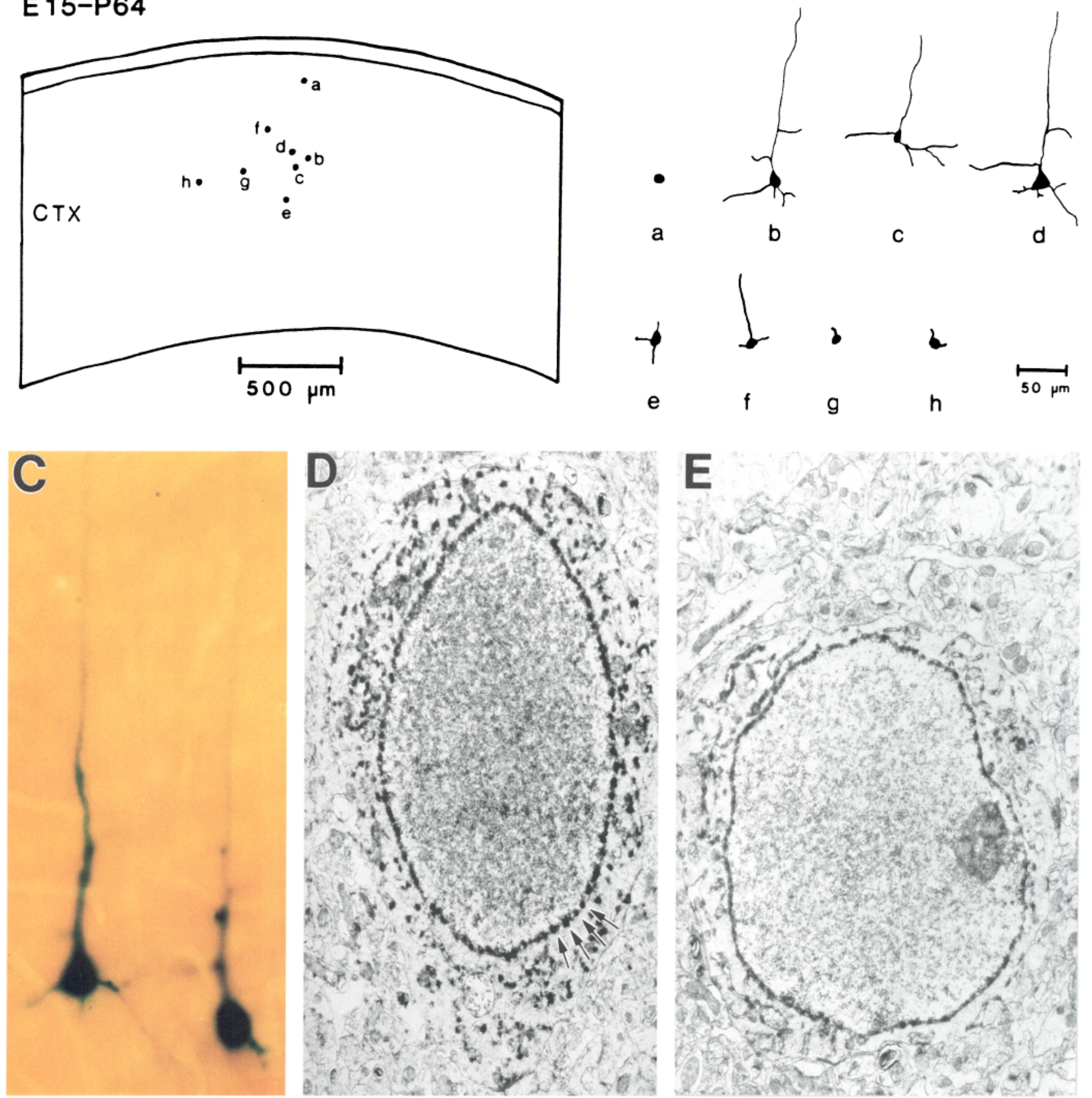

Figure 7. Reconstruction of a clone containing exclusively pyramidal neurons that was taken from the dorsolateral part of the visual cortex of a rat brain injected with retrovirus at E15 and perfused at P64, and examples of the morphology of its constituent cells at the light and electron microscopic levels. $A$, The eight-cell clone was reconstructed by superimposing the position of lacZ-positive cells (represented by dots $a-h)$ in three sequential camera lucida tracings of $100-\mu \mathrm{m}$-thick sections. The clone was $550 \mu \mathrm{m}$ wide and was separated from any other labeled cell by more than $800 \mu \mathrm{m}$. The camera lucida drawing in $B$ shows that at the light microscopic level the morphological detail of the individual lacZ-positive cells was quite variable. Some cells could be readily identified as pyramidal neurons (e.g., cells $b$ and $d$ ), whereas the phenotypic identity of others was difficult to discern because of limited process staining (e.g., cells $a$ and $g$ ). A systematic examination of each cell at the ultrastructural level revealed that the entire clone was composed of pyramidal neurons. $C$, Bright-field photomicrograph from a plastic-embedded $100 \mu \mathrm{m}$ Vibratome section of two members of the clone exhibiting morphologies characteristic of pyramidal cells. The cell on the left corresponds to cell $d$, and the one on the right, to cell b. $D$ and $E$, Electron micrographs of two of the lacZ-positive cells from this clone; $D$ shows the ultrastructural appearance of cell $f$, and $E$, the appearance of cell $g$. In both cells the histochemical reaction product encircling the nucleus has a beaded appearance (e.g., arrows in $D$ ). Note that cell $f$ could be recognized as a neuron at the light microscopic level because of its characteristic pattern of stained processes, whereas cell $g$ could not be definitively recognized. However, ultrastructural analysis indicated that cell $g$ was also a pyramidal neuron. $C T X$, cortex. Magnification: $C, 400 \times ; D, 7400 \times ; E, 7800 \times$. 
A

\section{E16-P83}
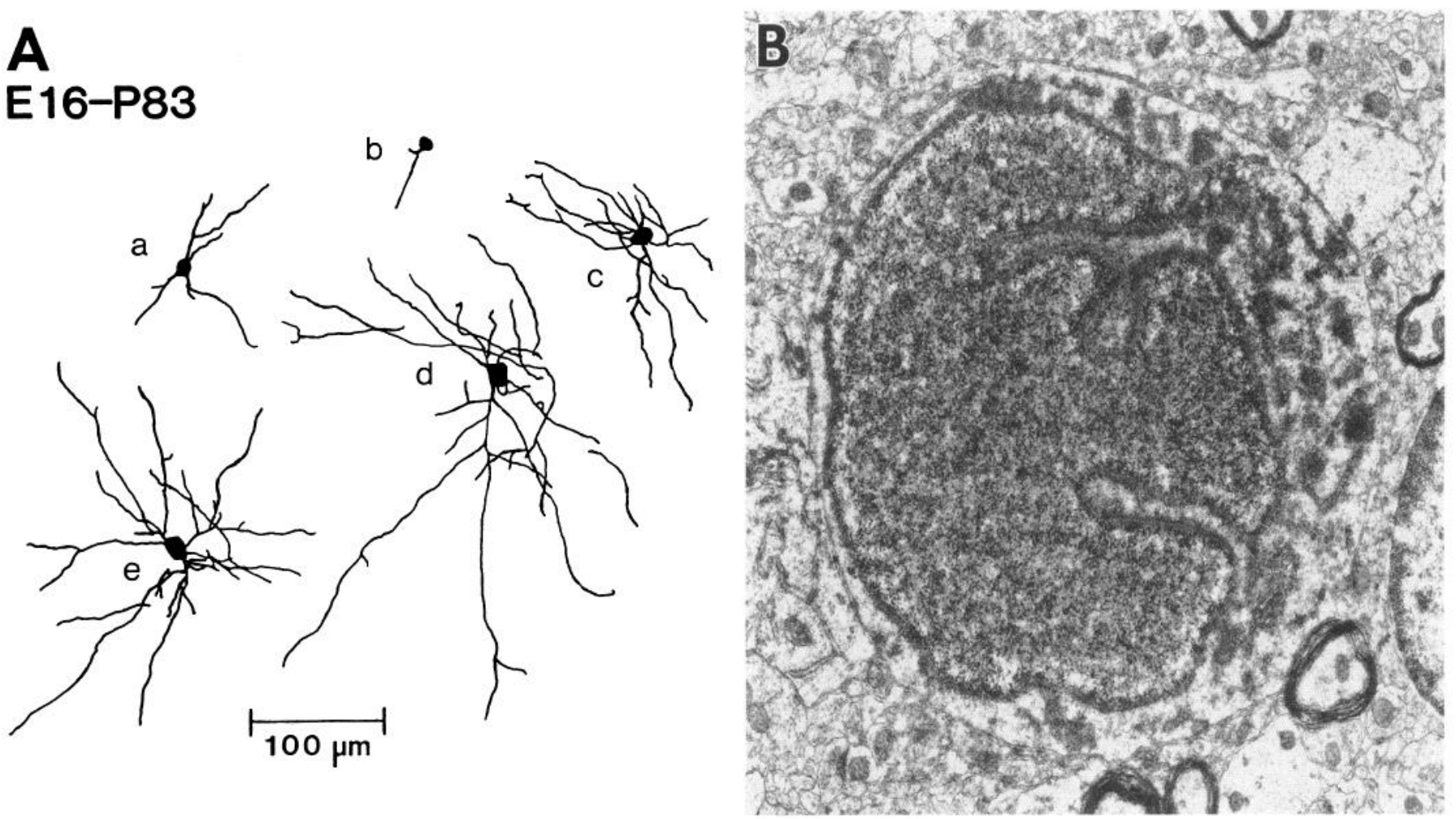

Figure 8. Illustration of a clone containing five nonpyramidal neurons from the visual cortex of a rat brain injected with retrovirus at E16 and perfused at P83. A, Camera lucida drawings of the five clonally related neurons. Judging by their elaborate process staining and similar morphologies, cells $a, c, d$, and $e$ exhibit the characteristics of multipolar nonpyramidal neurons. Note, though, that the phenotype of cell $b$ could not be established on the basis of its light microscopic appearance. However, at the ultrastructural level, it showed features characteristic of nonpyramidal neurons, as shown by the electron micrograph in $B$. It had a crenulated nuclear outline and a densely stained nucleus, and it received both symmetrical and asymmetrical synapses (not shown). Magnification $(B), 9800 \times$.

Table 2. Characteristics of individual neuronal clones

\begin{tabular}{|c|c|c|c|c|c|c|c|}
\hline $\begin{array}{l}\text { Age at } \\
\text { injection- } \\
\text { age at } \\
\text { perfusion }\end{array}$ & Phenotype of cells & $\begin{array}{l}\text { Number } \\
\text { of cells } \\
\text { per clone }\end{array}$ & $\begin{array}{l}\text { Location } \\
\text { (layer) }\end{array}$ & Cortical region & $\begin{array}{l}\text { Tangential dimen- } \\
\text { sions of clone }\end{array}$ & $\begin{array}{l}\text { Maximum } \\
\text { tangential } \\
\text { distance } \\
\text { between } \\
\text { cells in clone }\end{array}$ & $\begin{array}{l}\text { Nearest } \\
\text { unrelated } \\
\text { lacZ(+) } \\
\text { cell }\end{array}$ \\
\hline E16-P88 & Neurons (pyramidal) & 2 & 4 & Dorsal & $100 \times 45 \mu \mathrm{m}$ & $110 \mu \mathrm{m}$ & $540 \mu \mathrm{m}$ \\
\hline E15-P64 & Neurons (nonpyramidal) & 2 & 4 & Lateral & $400 \times 100 \mu \mathrm{m}$ & $400 \mu \mathrm{m}$ & $550 \mu \mathrm{m}$ \\
\hline E16-P83 & Neurons (nonpyramidal) & 2 & 4 & Lateral & $400 \times 200 \mu \mathrm{m}$ & $400 \mu \mathrm{m}$ & $850 \mu \mathrm{m}$ \\
\hline E16-P126 & Neurons $^{a}$ (nonpyramidal) & 2 & $4-5$ & Lateral & $30 \times 80 \mu \mathrm{m}$ & $85 \mu \mathrm{m}$ & $520 \mu \mathrm{m}$ \\
\hline E15-P64 & Neurons (nonpyramidal) & 2 & $4-5$ & Lateral & $50 \times 100 \mu \mathrm{m}$ & $100 \mu \mathrm{m}$ & $600 \mu \mathrm{m}$ \\
\hline E16-P88 & $\begin{array}{l}\text { Neurons (pyramidal and } \\
\text { nonpyramidal) }\end{array}$ & 2 & $2-4$ & Dorsolateral & $80 \times 85 \mu \mathrm{m}$ & $115 \mu \mathrm{m}$ & $595 \mu \mathrm{m}$ \\
\hline E16-P83 & Neurons (pyramidal) & 3 & 4 & Dorsal & $300 \times 100 \mu \mathrm{m}$ & $250 \mu \mathrm{m}$ & $800 \mu \mathrm{m}$ \\
\hline E16-P83 & Neurons (pyramidal) & 4 & $2-4$ & Medial & $200 \times 100 \mu \mathrm{m}$ & $100 \mu \mathrm{m}$ & $800 \mu \mathrm{m}$ \\
\hline E16-P88 & Neurons (nonpyramidal) & 4 & $4-6$ & Lateral & $100 \times 525 \mu \mathrm{m}$ & $405 \mu \mathrm{m}$ & $700 \mu \mathrm{m}$ \\
\hline E16-P88 & Neurons (pyramidal) & 4 & $2-4$ & Lateral & $530 \times 130 \mu \mathrm{m}$ & $430 \mu \mathrm{m}$ & $595 \mu \mathrm{m}$ \\
\hline E16-P83 & Neurons (nonpyramidal) & $4 / 5^{b}$ & $2 / 3$ & Medial & $300 \times 500 \mu \mathrm{m}$ & $100 \mu \mathrm{m}$ & $700 \mu \mathrm{m}$ \\
\hline E15-P95 & Neurons (pyramidal) & 6 & $2-4$ & Dorsolateral & $250 \times 145 \mu \mathrm{m}$ & $85 \mu \mathrm{m}$ & $500 \mu \mathrm{m}$ \\
\hline E15-P64 & Neurons (pyramidal) & $6 / 7^{b}$ & $2-4$ & Dorsolateral & $150 \times 100 \mu \mathrm{m}$ & $100 \mu \mathrm{m}$ & $500 \mu \mathrm{m}$ \\
\hline E15-P64 & Neurons (pyramidal) & $4 / 7^{b}$ & $2-4$ & Dorsal & $250 \times 300 \mu \mathrm{m}$ & $200 \mu \mathrm{m}$ & $500 \mu \mathrm{m}$ \\
\hline E15-P64 & Neurons (pyramidal) & 8 & $2-5$ & Dorsolateral & $550 \times 200 \mu \mathrm{m}$ & $200 \mu \mathrm{m}$ & $800 \mu \mathrm{m}$ \\
\hline E15-P64 & Neurons (pyramidal) & 9 & $2-4$ & Dorsal & $1350 \times 400 \mu \mathrm{m}$ & $450 \mu \mathrm{m}$ & $1100 \mu \mathrm{m}$ \\
\hline
\end{tabular}

E, embryonic day; $P$, postnatal day.

- Identified on the basis of light microscopic examination alone.

${ }^{b}$ Numerator represents number of cells identified by electron microscopy; denominator represents the total number of cells in the clone. 
A

\section{E16-P83}

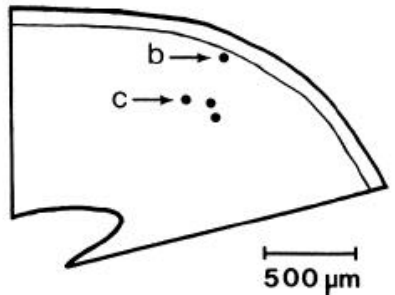

Figure 9. Illustration of a clone composed of four pyramidal neurons in the medial aspect of the cerebral cortex of a rat injected with retrovirus at E16 and perfused at adulthood. $A$ shows the distribution of the four cells in the cortex obtained by superimposing two serial $100 \mu \mathrm{m}$ coronal sections. $B$ and $C$ show the ultrastructural appearance of cells $b$ and $c$, respectively. The histochemical reaction product is prominently associated with the endoplasmic reticulum (asterisks in $B$ and $C$ ) and the nuclear membrane. The box in $B$ outlines the figure shown in $D$, a high-magnification electron micrograph of two symmetrical synapses (arrows) contacting the soma of cell $b$. Magnification: $B$ and $C, 7800 \times ; D, 42,000 \times$.
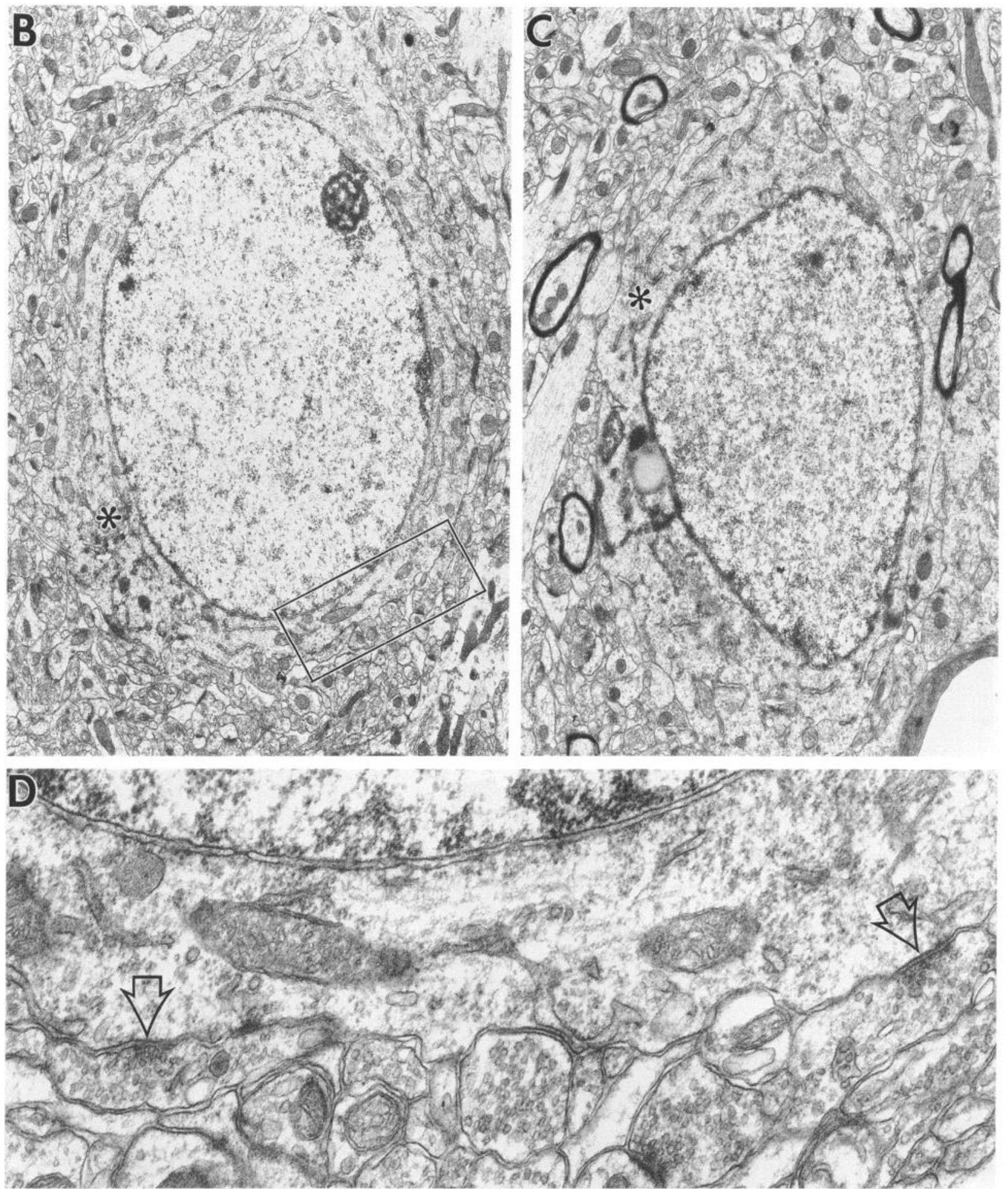
As expected, neuronal clones resulting from an E15 injection were larger (mean number of cells, 6.0) than clones resulting from an E16 injection (mean number of cells, 3.1). This difference in clone size was also evident when pyramidal and nonpyramidal cells were considered separately. For example, pyramidal cell clones contained 4.3 cells following E16 injections, and 7.4 cells following E15 injections. This is further evidence for a difference in the mechanisms generating pyramidal neurons and nonpyramidal neurons and emphasizes that clone size is a function of progenitor cell type as well as the stage of development at which the progenitor cell is tagged.

Clones composed of pyramidal neurons. At the ultrastructural level pyramidal cells have a number of distinctive features. Pyramidal neurons usually exhibit a round or oval nucleus, which is relatively pale and contains evenly distributed heterochromatin. Their cytoplasm contains an array of loosely packed organelles, including endoplasmic reticulum and mitochondria. The sections through the cell body often intersect one of the large dendrites, basal or apical, extending from the soma. In addition, pyramidal neurons receive exclusively symmetrical axosomatic synapses (Fig. 9D), and we used the lack of asymmetrical axosomatic synapses (in a sample of no less than 30 thin sections per cell examined) to identify conclusively a lacZpositive neuron as a pyramidal cell. All of these features exhibited by pyramidal cells are revealed in the electron micrographs of lacZ-positive neurons illustrated in Figures 7, $D$ and $E$, and $9 B-D$ from two different neuronal clones. In addition, in lacZpositive pyramidal cells the $\beta$-galactosidase histochemical reaction product is predominantly associated with the endoplasmic reticulum and nuclear membrane, where it often has a beaded appearance (Fig. $7 D$, arrows).

Nine of the 16 neuronal clones examined here were pyramidal cell clones, in which every cell examined at the ultrastructural level did fulfill the minimum criteria for a pyramidal neuron, for example, the presence of solely symmetrical axosomatic synapses. The pyramidal cell clones encountered contained from two to nine cells.

Clones composed of nonpyramidal neurons. Nonpyramidal neurons have nuclei that invariably show irregular outlines and invaginations and typically appear more electron dense than the nuclei of pyramidal neurons (Jones and Powell, 1970; Peters, 1985). They display varying amounts of perinuclear cytoplasm containing a complement of organelles often including parallel arrays of granular endoplasmic reticulum. However, the feature that distinguishes them unequivocally from pyramidal neurons is that they receive both symmetrical and asymmetrical axosomatic synapses (Colonnier, 1981; Peters, 1985). Not only did we find asymmetrical axosomatic synapses on every cell classified as a nonpyramidal cell, but these cells also had the characteristic invaginated nuclei.

A consistent difference between lacZ-positive pyramidal and nonpyramidal neurons is that the nuclei of nonpyramidal cells appear more intensely stained than those of pyramidal neurons (Figs. $8 B, 10 C, D$ ). The cause of the intense staining of nonpyramidal cell nuclei is not known, but became a useful feature to assist in the identification of nonpyramidal cells. LacZ-positive nonpyramidal cells also exhibited reaction product around their nuclear envelope and in association with a number of cytoplasmic organelles including endoplasmic reticulum.

Five of the 16 neuronal clones examined contained exclusively nonpyramidal cells ranging from two to five cells each. With one exception, all of the neuronal clones examined had exclusively pyramidal cells or nonpyramidal cells. The sole exception was a clone from an E16 injection that contained one pyramidal neuron and one nonpyramidal neuron (Table 3). It was not possible to determine if the cells arose from a bipotential progenitor cell or from two different progenitor cells situated near one another in the ventricular zone (Parnavelas et al., 1991).

\section{Discrete groups of lacZ-positive cells containing a mixture of neurons and glia}

Two clones were encountered that contained a mixture of neurons and glia (see Table 3); one contained three astrocytes and two nonpyramidal cells, while the other contained a group of oligodendrocytes and a single neuron (Table 3). However, in neither of the mixed neuronal/glial clones were the two different cell types intermingled with onc another. In the mixed oligodendrocyte/neuron clone the single neuron was displaced from the cluster of 17 oligodendrocytes by $200 \mu \mathrm{m}$ in the lateral plane (Fig. 11A). Similarly, the two neurons belonging to the astrocyte/ neuron clone were situated in layer 2 , whereas the three astrocytes were tightly clustered together at the layer $3 / 4$ border. In each case our criteria for the definition of clones require that we include the neuron(s) and glial cells in the same clone. In addition to the possibility that these clones arose from multipotential precursors, it is formally possible that the glia are derived from one progenitor cell while the neurons are derived from a separate, nearby progenitor cell. It is also conceivable that a single progenitor cell first generated cells of one type, followed by cells of the other type, a situation that would be consistent with the generation of homogeneous clones described above. Our data cannot distinguish between these alternatives.

\section{Intraclonal similarity in the pattern of $\beta$-galactosidase expression}

In addition to the cell-type-specific expression of $\beta$-galactosidase observed among lacZ-positive cells (e.g., oligodendrocytes and nonpyramidal cells are generally more densely stained than astrocytes and pyramidal cells), a further distinction in the $\beta$-galactosidase expression pattern within clones was evident. Individual cells within the same clone tend to exhibit a very similar pattern of $\beta$-galactosidase expression by histochemical detection methods. For example, the similarity in the distribution and intensity of reaction product is quite apparent in clones containing exclusively pyramidal neurons (see Figs. 7, 9). As in all pyramidal cells, the reaction product is associated with the nuclear membrane and endoplasmic reticulum (Fig. 9B,C, asterisks), but moreover, cells within the same pyramidal neuron clone display reaction product of very comparable densities. All cells in the four-cell clone shown in Figure 9 were weakly labeled, whereas the eight cells illustrated in Figure 7 uniformly exhibited heavier staining. Figure 10 provides another example of this intraclonal similarity in the two-cell clone of nonpyramidal neurons. The cells were strikingly similar at the ultrastructural level and exhibited the same pattern and intensity of staining. Finally, the similarity in the expression of $\beta$-galactosidase was also evident in the glial clones examined. In the clone of 17 astrocytes examined (see Fig. 5), there was a striking resemblance in the overall shape of their nuclei and somata, and the distribution and intensity of the $\beta$-galactosidase staining were practically identical in every cell.

The pronounced consistency of the density and disposition of reaction product seen within individual cells of the same clone provides further support that a cluster of lacZ-positive cells is 
A

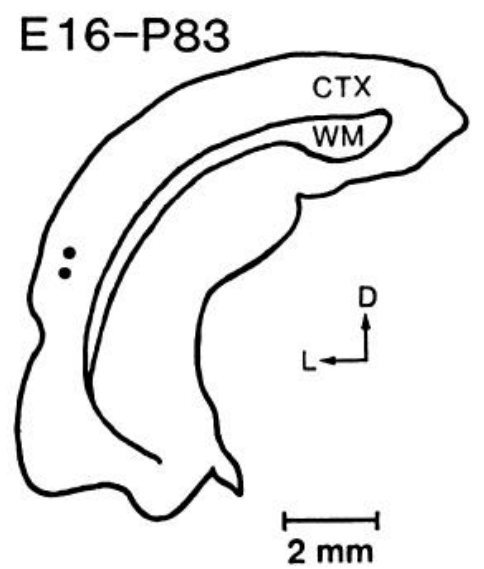

B

a

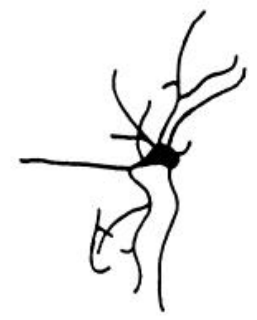

b

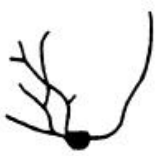

$\stackrel{\longmapsto 0 \mu \mathrm{m}}{5}$

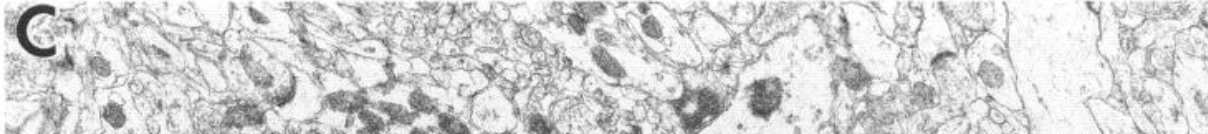

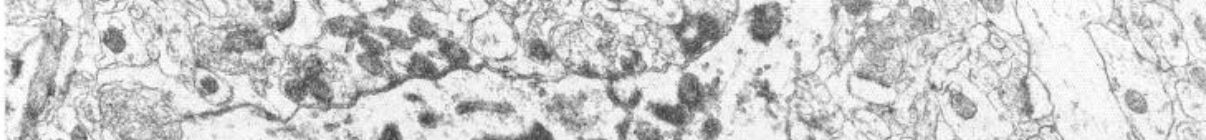

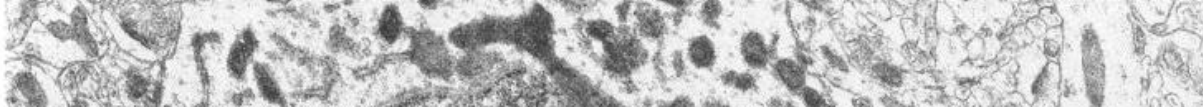

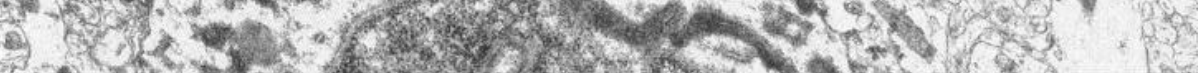

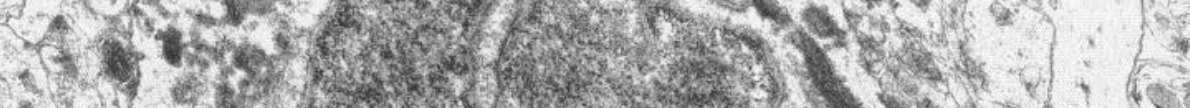

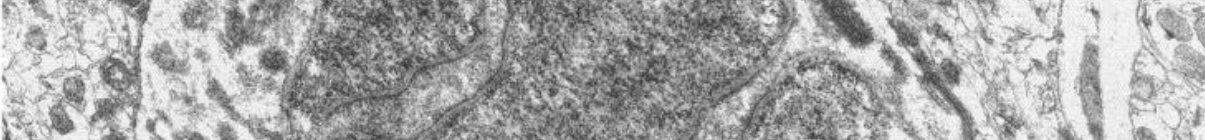

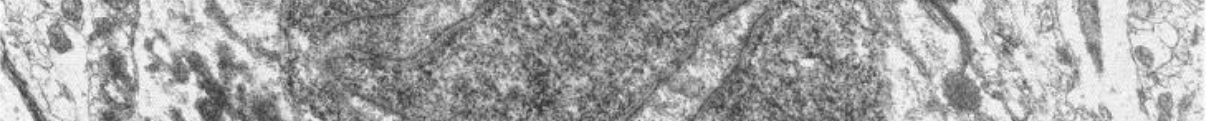



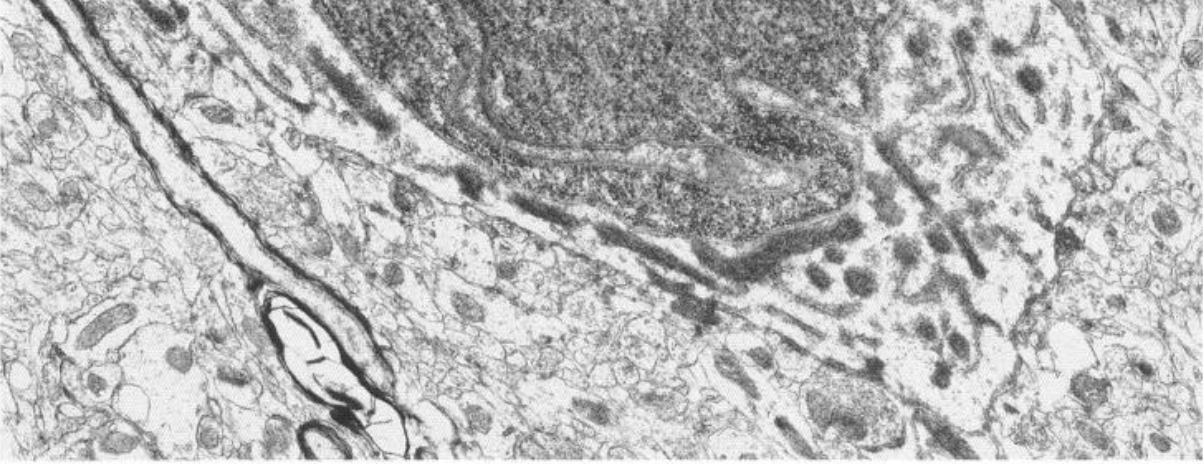

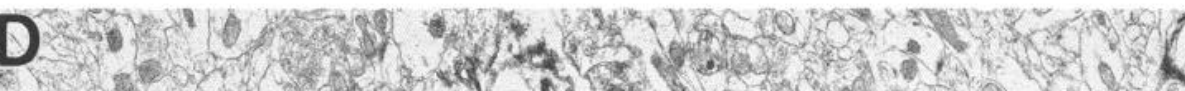

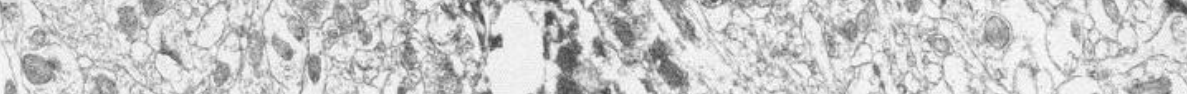
(5.5)

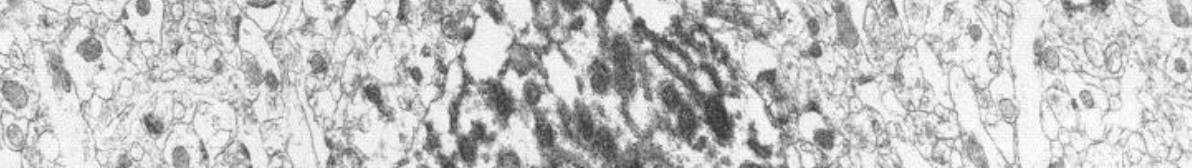
H.

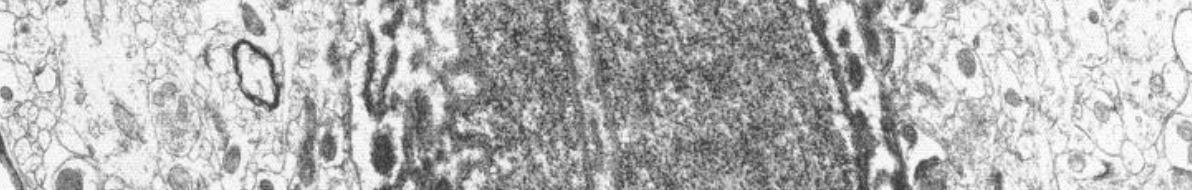

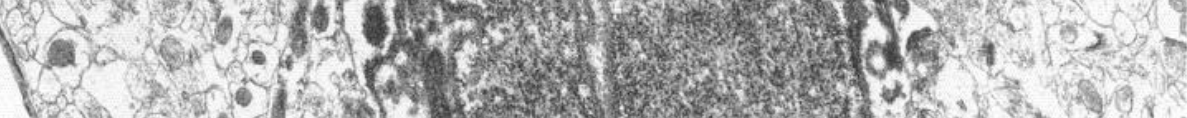

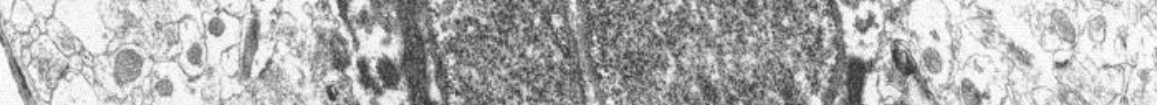

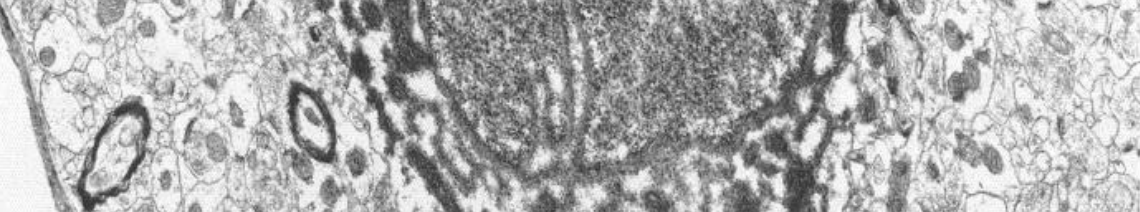

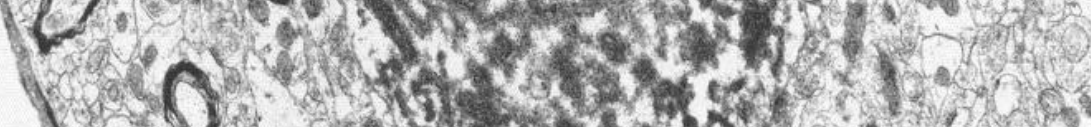

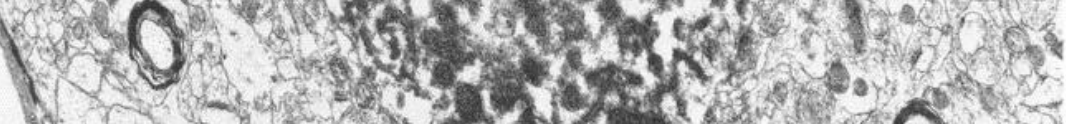
I. 
Table 3. Characteristics of clones containing a mixture of neuronal and glial cells

\begin{tabular}{|c|c|c|c|c|c|c|c|}
\hline $\begin{array}{l}\text { Age at } \\
\text { injection- } \\
\text { age at } \\
\text { perfusion }\end{array}$ & Phenotype of cells & $\begin{array}{l}\text { Number } \\
\text { of cells } \\
\text { per clone }\end{array}$ & $\begin{array}{l}\text { Iocation } \\
\text { (layer) }\end{array}$ & Cortical region & $\begin{array}{l}\text { Tangential dimen- } \\
\text { sions of clone }\end{array}$ & $\begin{array}{l}\text { Maximum } \\
\text { tangential } \\
\text { distance } \\
\text { between } \\
\text { cells in clone }\end{array}$ & $\begin{array}{l}\text { Nearest } \\
\text { unrelated } \\
\text { lacZ(+) } \\
\text { cell }\end{array}$ \\
\hline E16-P83 & $\begin{array}{l}3 \text { Astrocytes and } 2 \text { Non- } \\
\text { pyramidal neurons }\end{array}$ & 5 & $2-4$ & Dorsal & $250 \times 500 \mu \mathrm{m}$ & $150 \mu \mathrm{m}$ & $750 \mu \mathrm{m}$ \\
\hline E16-P83 & $\begin{array}{l}17 \text { Oligodendrocytes and } \\
1 \text { Nonpyramidal neuron }\end{array}$ & 18 & $\mathrm{GM}$ & Hippocampus & $\begin{array}{l}200 \times 200 \mu \mathrm{m}^{a} \\
400 \times 200 \mu \mathrm{m}^{b}\end{array}$ & $\begin{array}{r}50 \mu \mathrm{m}^{a} \\
200 \mu \mathrm{m}^{b}\end{array}$ & $700 \mu \mathrm{m}$ \\
\hline
\end{tabular}

E, embryonic day; $P$, postnatal day; GM, gray matter.

${ }^{a}$ Distances if clone consists of only oligodendrocytes.

${ }^{b}$ Distances if clone consists of oligodendrocytes and neuron.

in fact a clone. The strong similarity in the density of staining may be related to the site of integration of the retrovirus, although this has not yet been proven.

\section{Statistical significance of clonal composition}

We used a statistical test to evaluate the significance that clones found within the mature cerebral cortex, resulting from an injection of retrovirus at the onset of neurogenesis (E15 or E16), were composed of a homogeneous population of cells. First, we subdivided the clones into neuronal or non-neuronal clones and used the Binomial Test of Proportions (Snedecor and Cochran, 1980) to determine the probability that chance accounted for the homogeneous clones containing exclusively neurons or exclusively glia. The $P$ value obtained was $<0.0001$, indicating that it is extremely unlikely that the observed distribution of cells is explained by chance. Therefore, this result supports the alternative explanation that there are separate progenitor cells for neurons and glia in the ventricular zone of the developing telencephalon when neurons begin to withdraw from the mitotic cycle.

Similarly, we used the Binomial Test of Proportions to determine the probability that chance accounted for the solely pyramidal or nonpyramidal neuronal clones observed. The $P$ value obtained was $<0.001$, which indicates that it is highly unlikely that the homogeneity among neuronal clones arose by chance. Instead, this indicates that homogeneous neuronal clones arisc, at least in part, because there are separate progenitor cells in the ventricular zone for pyramidal and nonpyramidal cells by the onset of neurogenesis.

\section{Discussion}

In this study, we found that when progenitor cells of the rat telencephalic ventricular zone were marked with a retroviral lineage tracer and, subsequently, lineally related cells in the rat cerebral cortex were classified according to well-established ultrastructural criteria, essentially all of the progeny of an infected progenitor cell possessed the same phenotype. Specifically, we observed, with few exceptions, that all clones were composed of exclusively astrocytes, oligodendrocytes, or neurons. Moreover, we previously demonstrated that the neuronal clones could be further subdivided into clones containing exclusively pyramidal cells or nonpyramidal cells, but not both (Parnavelas et al., 1991). Here, we have substantiated the finding of varied neuronal clones in a number of ways to highlight the manifestation of cell type homogeneity of clones. Since progenitor cells of the telencephalon were infected with retrovirus at the onset of cortical neurogenesis, our finding that clones are homogeneous with respect to cell type suggests that some individual progenitor cells have undergone lineage restrictions by the time cortical neurogenesis has begun. Furthermore, this result implies that in the ventricular zone, by the onset of neurogenesis, there are separate progenitor cells for neurons, astrocytes, and oligodendrocytes, as suggested by Luskin et al. (1988), as well as distinct progenitor cells for pyramidal and nonpyramidal neurons.

Our finding, that clones are homogeneous with respect to the cell types we considered, does not itself imply that telencephalic progenitor cells are committed to producing only one kind of cell. Accordingly, one cannot conclude that lineage plays a critical role in dictating a cell's identity simply because all the members of a clone comprise a particular ensemble of cell types or share the same phenotype. For example, the differentiation of cells in the Drosophila eye ommatidium follows a stereotypical pattern of development that is now known to be regulated by cell-cell interactions (Banerjee and Zipursky, 1990). However, certain principles and features of cortical development support the conclusion that the phenotype of a cell in the cerebral cortex cannot be strictly determined environmentally, but there must be a genetic component as well. Most significantly, the local environment for each member of a clone is often different during the various phases of its development (for a review of cortical development, see McConnell, 1991). First, clonal cohorts, particularly neurons, are born at different times when the milieu of the ventricular zone is undergoing changes. Second,

\section{$\leftarrow$}

Figure 10. Illustration demonstrating the similarity in the light and electron microscopic appearance of the two cells composing a nonpyramidal clone in the cerebral cortex from a rat brain injected with retrovirus at E16 and perfused at adulthood. $A$ shows the position of the two lacZpositive cells in the lateral aspect of the cerebral cortex reconstructed by superimposing four serial $100 \mu \mathrm{m}$ sections. The cells were separated from any other stained cells by $850 \mu \mathrm{m}$ in the lateral dimension of the cortex. $B$, Camera lucida drawings of the light microscopic appearance of both cells. $C$ and $D$, Electron micrographs of the two lacZ-positive cells; $C$ shows the ultrastructural appearance of cell $a$, and $D$, the appearance of cell $b$. Note the striking similarity in their fine structure and pattern of histochemical staining. Both have deeply indented nuclei and heavily stained nuclear membranes, nucleoplasm, and cytoplasmic organelles. $C T X$, cortex; $W M$, white matter; $D$, dorsal; $L$, lateral. Magnification: $C, 9200 \times ; D$, $8400 \times$. 

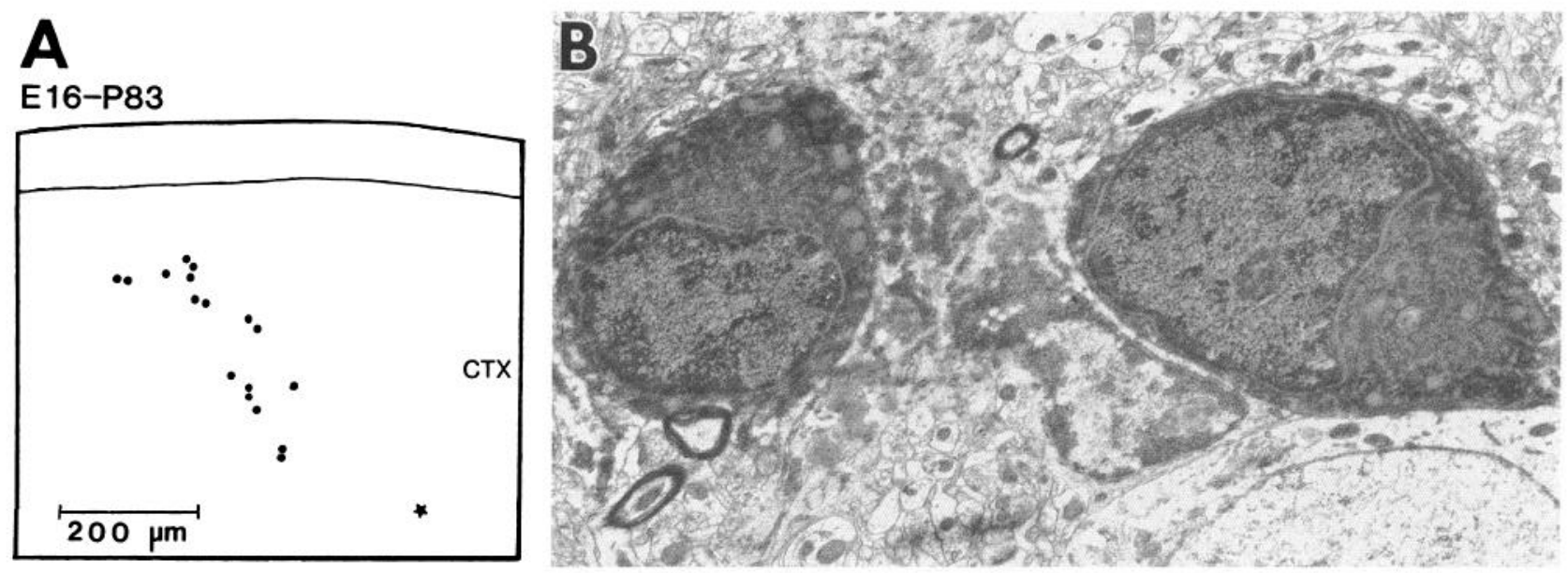

Figure 11. Positional relationships between lacZ-positive cells in a clone from a brain injected with retrovirus at E16 and perfused at P83. $A$ shows a reconstruction of a clone situated in the gray matter containing 17 closely spaced oligodendrocytes and a single neuron (star), which is situated $200 \mu \mathrm{m}$ away from the nearest lacZ-positive oligodendrocyte. The clone measured $450 \mu \mathrm{m}$ in its maximum lateral extent and was present in three $100 \mu \mathrm{m}$ serial Vibratome sections. It was not possible to determine whether the single neuron arose from the same progenitor cell as the oligodendrocytes or from a separate progenitor cell (see Discussion for a consideration of alternatives). The electron micrograph in $B$ shows two nearby lacZ-positive oligodendrocytes from the clone shown in $A$. $C T X$, cortex. Magnification $(B), 6500 \times$.

clonal cohorts traverse different terrains where they are subjected to different environmental influences before reaching their final destination in the cortical plate. And third, clonal cohorts frequently establish residence in distinct and dissimilar positions in the developing cerebral cortex, such as disparate laminar positions, that differentiate at different times. Thus, during the development of the cerebral cortex, we found that although clonal cohorts are exposed to various environments, they nevertheless independently express the same phenotypic properties. Moreover, two unrelated cells that are exposed to virtually identical environments during their development as a consequence of their simultaneous generation in the ventricular zone, their concurrent migration to the cortical plate, and their residence in the same layer, frequently have different phenotypes. An example of this would be a pyramidal cell and nonpyramidal cell located adjacent to one another in a particular cortical layer. Taken together with our results, these aspects of cortical development support the idea that the ventricular zone is not an undifferentiated layer of dividing cells, but rather a mosaic of different progenitor cell types. The descendants of the progenitor cells acquire their specific phenotype in accordance with the phenotype of the progenitor cell from which they are derived.

The lineage restrictions revealed in the cerebral cortex by our study are in contrast to what occurs in other regions of the CNS (optic tectum, Galileo et al., 1990; retina, Turner and Cepko, 1987; Holt et al., 1988; Wetts and Fraser, 1988) where progenitor cells may remain multipotential during the period of neurogenesis and give rise to more than one cell type until their final cell division. In addition, a number of studies on the development of the vertebrate PNS have underscored the role of environmental factors in dictating the phenotype of cells (for review, see Anderson, 1992). Nonetheless, as development proceeds throughout the CNS and PNS, the potential for differentiation of a progenitor cell or its progeny becomes progressively more restricted. While our results do not establish that lineage is the sole determinant of cell phenotype in the cerebral cortex, they do suggest that lineage plays an instrumental role. Additional experiments are required to elucidate the influence of extrinsic factors, such as cell-cell interactions or position- dependent cues, in dictating the fate of cells in the cerebral cortex.

\section{Grounds for considering that lacZ-positive cell clusters are clones}

Several lines of evidence support the premise that discrete clusters of lacZ-positive cells found in the rat cerebral cortex resulting from an intraventricular injection of retrovirus at the onset of neurogenesis (E15 or E16) are likely to be clonal relatives. However, another study (Walsh and Cepko, 1992) has provided evidence that the progeny of some telencephalic progenitor cells are widely dispersed, occasionally even over several millimeters, in the cerebral cortex.

Walsh and Cepko (1992) injected a library of genetically distinct retroviruses into the cerebral ventricles of rat embryos at E15 or E17. After localizing lacZ-positive cells by histochemistry, PCR was used to amplify and evaluate the specific viral construct present in each histochemically stained cell. It was assumed that if the same viral construct occurred in two different cells that these cells were the progeny of the same progenitor cell. They examined the discrepancy between establishing clonal boundaries by geometric criteria (observed clusters of lacZ-positive cells) and establishing clonality using PCR in order to determine the frequency of the "lumping" together of cells from different clones. Using their criteria to detect maximally the probability that our discrete groups are polyclones, we found only a $3 \%$ chance of lumping errors for the majority of clusters we considered to be clones (44\%). For another $25 \%$ of our assigned clones there was a $13 \%$ lumping error, and for only one clone, which had a dimension greater than $1000 \mu \mathrm{m}$, was the lumping error greater than $23 \%$. This large cluster contained nine lacZ-positive cells, all of which were exclusively pyramidal neurons. Thus, it is reasonable to conclude that most of the clusters we examined did indeed constitute a set of clonally related cells.

Our general conclusion, that clones are usually homogeneous, would still hold even if what we considered to be a complete clone was in fact only a subclone. However, we cannot rule out the possibilities that some clonal cohorts died, failed to express 
$\beta$-galactosidase, or escaped detection by migrating to a different location than the designated cluster of lacZ-positive cells. In our experiments, though, if discrete clusters of $\beta$-galactosidase-positive cells contained the offspring of more than one precursor cell, we would have expected to observe more heterogeneity within each cell group. Rather, we found that clones were virtually always composed of a single cell type. Collectively, these observations are consistent with the premise that, in most instances, discrete groups of $\beta$-galactosidase-positive cells are in fact clonally related. Although Walsh and Cepko (1992) have emphasized the widespread nature of nonradial clones, even in their study the majority of descendants of the progenitor cells migrated radially away from the ventricular zone and established clustered groups of lineally related cells. Therefore, our results and those of Walsh and Cepko are not as contradictory as one may initially believe. A common conclusion that can be drawn is that while there is a certain amount of dispersion, most cells migrate radially away from the ventricular zone.

The chimeric mice produced by Nakatsuji et al. (1991) using an cmbryonic stem cell line expressing the lac $Z$ gene provides additional evidence that cells situated next to or close to one another in the ventricular zone give rise to neurons that assume contiguous positions in the cerebral cortex. In the mice examined by Nakatsuji et al. (1991), radial patches of $\beta$-galactosidasestained neurons were observed extending across the entire developing cerebral cortex, suggesting that a radial alignment is maintained after neurons complete their migration. Therefore, the clones of dispersed cells described by Walsh and Cepko (1992) may be the exception to the rule and ultimately shed light on why some progenitor cells send their progeny to distant areas whereas the progeny of other cells congregate in one location.

Additional findings that support the interpretation that discrete groups of $\beta$-galactosidase-positive cells represent the progeny of individual progenitor cells come from our previous experiments, in which we showed that in vitro the number of isolated telencephalic cell clusters of lacZ-positive cells was a function of the amount of virus applied, although the size of the clones (number of cells per cluster) was independent of the amount of virus added. Similarly, Austin and Cepko (1990) in their in vivo studies reported that after virus was injected into the cerebral ventricles of the prenatal rodent brain during the period of neurogenesis, the number of lacZ-positivc clustcrs in the cerebral cortex varied linearly with the number of virus particles injected. Thus, their studies concurred with the idea that discrete clusters of lacZ-positive cells contain clonally related cells. It is extremely difficult to reconcile how this result could arise if, as suggested by Walsh and Cepko (1992), the progeny of individual progenitor cells become widely scattered in the brain. A more random pattern of migration than what is believed to occur (Nakatsuji et al., 1991; for review, see Rakic, 1988) would not lead to detectable clusters of lacZ-positive cells whose frequency varies as a function of the amount of virus administered. Therefore, the results of several studies support the view that discrete groups of lacZ-positive cells in the cerebral cortex, such as the ones studied here, are clonally related. Moreover, the probability in our study that the homogeneous clonal composition observed among the clones analyzed is due to chance was shown by the Binomial Test of Proportions to be extremely unlikely $(P<0.001)$.

Furthermore, although more difficult to quantify, indirect but compelling support for the belief that discrete groups of lacZpositive cells represent clones is related to the observed simi- larities in the pattern of the $\beta$-galactosidase histochemical staining among members of a cluster of lacZ-positive cells of the same phenotype. We observed that, at the ultrastructural level, the staining intensity and intracellular distribution of the $\beta$-galactosidase histochemical reaction product were remarkably similar in each of the cells comprising a presumed clone. These features were not necessarily evident at the light microscopic level, but generally quite prominent at the electron microscopic level. For example, at the light microscopic level, even within the same clone some lacZ-positive cells had stained processes while others did not. Nonetheless, at the ultrastructural level, in nearly every cluster of lacZ-positive cells there was a correlation between the cell type and staining pattern. Most significantly, we found that cells fulfilling the ultrastructural criteria for oligodendrocytes and nonpyramidal cells usually displayed an electron-dense nucleus laden with reaction product whereas pyramidal cells and astrocytes generally did not.

In addition to the interclonal similarities of the cell-typespecific staining properties revealed in this study, we also took advantage of the finding that clonal cohorts, in a given clone, exhibit qualitative similarities in their staining intensity (intraclonal similarities). For instance, all the lacZ-positive cells were heavily stained in some clones, while in others all of the clonal cohorts were lightly stained, regardless of cell type. For example, compare the light staining of all the clonally related pyramidal cells in Figure 9 to the much more substantial staining of all the pyramidal cells in Figure 7, though still lighter than the staining occurring in nonpyramidal neurons (e.g., Figs. 8, 10). It is quite conceivable that the similarities in staining within a cluster of lacZ-positive cells are the consequence of all descendants of an infected cell regulating $\beta$-galactosidase expression comparably due to each cell possessing the same inherited integration site for the retroviral genome (Nolan et al., 1988).

\section{Types of progenitor cells in the developing mammalian telencephalon}

The major aim of this study was to determine whether there are different kinds of progenitor cells in the ventricular zone of the developing rat telencephalon by the onset of cortical neurogenesis. Here we have taken advantage of retrovirally mediated gene transfer to investigate specifically whether there are separate progenitor cells for the major subtypes of neurons and glia in the cerebral cortex: the astrocytes, oligodendrocytes, pyramidal neurons, and nonpyramidal neurons. Furthermore, this was the first study to use unequivocal criteria, which relied on the ultrastructural characteristics of lacZ-positive cells, to distinguish definitively the phenotypes of clonally related cells.

The observed homogeneity of cell types occurring within practically all clones examined at the ultrastructural level suggests that there are separate progenitor cells for each of the major subtypes of cells in the cerebral cortex. Furthermore, the different cell types in the two mixed neuronal-glial clones encountered occupied nonoverlapping locations within the cluster. We reasoned that this arrangement could arise either by (1) the retrovirus infecting a multipotential or bipotential progenitor cell, resulting in a heterogeneous clone, or (2) the infection of different progenitor cells originally situated close to one another in the ventricular zone, whose individual progeny take up positions in the cerebral cortex relatively close to one another. We favor the second alternative because the two different cell types occurring in the same cluster were not intermingled with each other. However, the results do not preclude the occurrence of either possibility. To distinguish between these possibilities, we 
would need to know the integration site of the lacZ gene in all of the lacZ-positive cells comprising each mixed clone. Unfortunately, the methods for ascertaining integration sites are not presently compatible with the electron microscopic analysis undertaken.

Although still not settled, other in vivo and in vitro studies analyzing glial lineage relationships in the forebrain have also concluded that there are distinct lineages for astrocytes and oligodendrocytes (for review, see Skoff and Knapp, 1991; Cameron and Rakic, 1991). Recently, Vaysse and Goldman (1990) have demonstrated that, when retroviral lineage tracing is combined with cell-type-specific markers in order to identify the phenotype of cells in vitro, lineages for astrocytes and oligodendrocytes have diverged in the rat striatum by the time of birth (E22). This result agrees with our findings from earlier in vitro studies from the developing telencephalon of the mouse, where we also used retroviral lineage tracing in conjunction with celltype-specific markers (Luskin et al., 1988). We suggested that by the onset of neurogenesis (E13 in the mouse), there are separate lineages for astrocytes and oligodendrocytes, as wcll as neurons. In the study described here, approximately $40 \%$ of the clones were composed exclusively of glial cells (nine clones). Presently there is no way to determine whether this matches the proportion of glial progenitor cells in the ventricular zone, or whether there are fewer glial progenitor cells than neuronal progenitor cells at the onset of neurogenesis.

Several morphological and immunohistochemical studies have reported that the embryonic brain contains very few glial cells other than the radial glial variety (see Cameron and Rakic, 1991). The low number of glial cells in immature brains, taken together with the compact cell packing density of lacZ-positive cells within the glial clones examined in this study, suggests that mitosis of glial cells is taking place locally in the cerebral cortex, once a glial progenitor cell has migrated to a location in the gray or white matter. Interestingly, an analysis of the composition of glial clones resulting from neonatal injections of the subventricular zone provided additional evidence that the lineages for astrocytes and oligodendrocytes are distinct in the cerebral cortex (McDermott et al., 1991).

However, other attempts to uncover how cell diversity arises in the mammalian CNS using cultured cells have provided evidence for a bipotential glial precursor cell, the O2A-progenitor cell, for astrocytes and oligodendrocytes in the rat optic nerve (for review, see Raff, 1989), and for a common precursor cell for neurons and glia in the developing septal region (Temple, 1989), although only a small proportion of the dividing cells were bipotential. In addition, in another tissue culture study using retroviral lineage tracers combined with cell-type-specific markers, Williams et al. (1991) revealed the existence of a small population of precursor cells in the embryonic telencephalon that produce neurons and oligodendrocytes. One possible explanation for the low percentage of bipotential cells $(<5 \%)$ is that the infections of the lineage tracer were made around the time that the population of progenitor cells were undergoing a transition from being multi- or bipotential, to having their potentials more restricted. In fact, this is suggested by the apparent absence of bipotential cells in the ventricular zone at E18, which is well into the period of neurogenesis (E16 was the last day a bipotential cell was reportcd betwcen E12 and E18). Alternatively, there may be a resident population of bipotential cells that constitute an exceedingly small fraction of the remaining progenitor cells. Hall and Landis (1991) have also shown, using retroviral mediated gene transfer, that the neuronal and non- neuronal cells of the rat superior cervical ganglion are derived from separate precursors. Therefore, lineage restrictions occur in the PNS as well as in the CNS.

Presumably, there must be a large population of multipotential precursor cells in the developing telencephalon in vivo as well, but at an earlier developmental stage than that studied so far in our lineage tracing experiments. Accordingly, if the phenotype of the progeny of progenitor cells becomes progressively more limited from one generation to the next, then genetic factors may be invoked, and influence the outcome of the fate adopted by cells in subsequent generations. Experiments in which retroviral lineage tracers are administered at younger ages should reveal when the lineage restrictions revealed for the cells of the cerebral cortex are first manifested. Nevertheless, our results suggest that the cerebral cortex may have devised a strategy for the generation of cell diversity that differs from the schemes elucidated elsewhere in the CNS. Our results raise the intriguing possibility that there may be a greater variety of progenitor cells in the ventricular zone of the telencephalon than previously anticipated. This may be the way that the developing cerebral cortex has chosen to regulate the production of the necessary types and numbers of cells.

The possibility of a still greater variety of progenitor cells in the developing telencephalon than appreciated already raises the question of just how many kinds of stem cells there are in the ventricular zone at the onset of neurogenesis. To a first approximation, the composition of the clones examined may be a reflection of the range of progenitor cell types. Hence, our work suggests that there are not less than four types of progenitor cells, one each for astrocytes, oligodendrocytes, pyramidal neurons, and nonpyramidal neurons. However, it does not rule out the possibility that there may be even more types of restricted or specialized progenitor cells. Neither do our results rule out the existence of a multipotential progenitor cell for neurons and glia or the different subclasses of neurons, such that some progenitor cells give rise to multiple cell classes whereas others have a more restricted phenotype. However, our study would suggest that the number of multipotential progenitor cells is small by the onset of neurogenesis.

By virtue of the fact that many of the larger neuronal clones encountered in our study span the upper and lower layers of the cerebral cortex, we have no compelling evidence to support directly the idea that cells of the supragranular layers are derived from different sets of progenitor cells than those of the infragranular layers, as suggested previously (Price and Thurlow, 1988). Moreover, since pyramidal and nonpyramidal cells occur in both the upper and lower layers of the rodent cerebral cortex, as do astrocytes and oligodendrocytes, there is no obvious reason to think that separate progenitor cells are needed to populate the cells of specific layers. Nonetheless, evidence from the transplantation studies has shown that the laminar fate of a cortical neuron is determined during or just following its final mitosis in the ventricular zone (McConnell and Kaznowski, 1991). Therefore, in the cerebral cortex, it appears that decisions about cell phenotype, which are made before the onset of cortical neurogenesis, are made before a neuron's laminar fate is slated. In general, though, cells in different layers can be of the same general class and from the same progenitor cell.

\section{Characteristics of cell-type-specific clones}

A major difference between neuronal and glial clones is that clones composed of astrocytes and oligodendrocytes generally contain a greater number of cells (range, 2-32 cells per clone; 
mean, 11.1 cells) than clones composed of neurons (range, 2-9 cells per clone; mean, 4.3 cells). This may reflect the fact that glial cells continue to be generated postnatally whereas cortical neurogenesis in the rat is restricted to the interval between approximately E15 and E21. If the retrovirus is administered at E15 or E16, assuming a cell cycle length of approximately 24 $\mathrm{hr}$, this will allow for the generation of only a limited number of neurons. The difference in the size of clones may also be related to whether the progenitor cells of neurons and glia undergo predominantly symmetrical or asymmetrical divisions. However, due to the inside-out pattern of neurogenesis in the cerebral cortex, neuronal progenitor cells are most likely to divide asymmetrically in order to generate cells destined for all cortical layers, whereas glial progenitor cells are more likely to divide symmetrically. The difference in the size of clones may also be related to the amount of cell death occurring, although no studies have specifically addressed the contribution, if any, of cell death to clonal size.

On average, despite the cell size differences between neuronal and glial clones, the dimensions of neuronal clones tended to be larger than the dimensions of glial clones, although some glial clones were spread out across a relatively large area. A rough approximation would be that, for both clusters of lacZpositive neurons and glia, the dimensions of a clone become larger as the number of cells in the clone increase. In addition, although the distance separating a clone from the nearest unrelated lacZ-positive cell was equivalent for neuronal and glial clones occurring in different cortical areas (see Tables 1,2), cells composing astrocyte and oligodendrocyte clones were more closely spaced than cells within neuronal clones. The maximum distance between any two cells within a neuronal clone ranged from $85 \mu \mathrm{m}$ to $450 \mu \mathrm{m}$, with an average of $250 \mu \mathrm{m}$ (Table 2), whereas the majority of cells within glial clones were quite closely spaced $(<50 \mu \mathrm{m})$. This suggests that some of the lacZ-positive glial cells may have been the offspring of precursor cells that divided in situ after migrating away from the ventricular zone. The studies of LeVine and Goldman (1988) suggest that this migration occurs postnatally, although it has not yet been determined when the lacZ-positive glial progenitor cell or its offspring migrate away from the proliferative zone lining the ventricles.

The neuronal clones examined spanned various combinations of layers, and in some instances the same clone was composed of cells from both the infragranular and supragranular layers. On average, the E15 injections tended to span more cortical layers than the E16 injections, consistent with the overall pattern of neurogenesis. Even though some layer 6 neurons are generated at E15 and E16 (Raedler and Raedler, 1978), which was when we injected the retroviral lineage tracer, lacZ-positive neurons very rarely occurred in layer 6 . The absence of lac $Z$-positive cells in layer 6 may be due to the retroviral lineage tracer not being histochemically detected until the infected progenitor cell had divided. In contrast, tritiated thymidine labels cells undergoing their last cycle of division. The outcome of these differences is that the lineage tracer would appear in daughters of the infected cells, resulting in lacZ-positive neurons residing more superficially in the cortex than radiolabeled cells following tritiated thymidine injections at the corresponding ages.

\section{References}

Anderson DJ (1992) Molecular control of neural development. In: An introduction to molecular neurobiology (Hall ZW, ed), pp 355-387. Sunderland, MA: Sinauer.
Austin CP, Cepko CL (1990) Cellular migration patterns in the developing mouse cerebral cortex. Development 110:713-732.

Banerjee U, Zipursky SL (1990) The role of cell-cell interaction in the development of the Drosophila visual system. Neuron 4:177-187.

Barfield JA, Parnavelas JG, Luskin MB (1990) Separate progenitor cells give rise to neurons, astrocytes and oligodendrocytes in the rat cerebral cortex. Soc Neurosci Abstr 16:1272.

Bonnerot C, Rocancourt D, Briand P, Grimber G, Nicolas J-F (1987) A $\beta$-galactosidase hybrid protein targeted to nuclei as a marker for developmental studies. Proc Natl Acad Sci USA 84:6795-6799.

Cameron RS, Rakic P (1991) Glial cell lineage in the cerebral cortex: a review and synthesis. Glia 4:124-137.

Cepko C (1990) Lineage analysis and immortalization of neural cells via retrovirus vectors. In: Neuromethods 16: molecular neurobiological techniques (Boulton A, Baker G, Campagnani AT, eds), pp 177-219, Clifton, NJ: Humana.

Colonnier M (1981) The electron-microscopic analysis of the neuronal organization of the cerebral cortex. In: The organization of the cerebral cortex (Schmitt FO, Worden FG, Adelman G, Dennis SG, eds), pp 125-152. Cambridge, MA: MIT Press.

Galileo DS, Gray GE, Owens GC, Majors J, Sanes JR (1990) Neurons and glia arise from a common progenitor in chicken optic tectum: demonstration with two retroviruses and cell type-specific antibodies. Proc Natl Acad Sci USA 87:458-462.

Hall AK, Landis SC (1991) Early commitment of precursor cells from the rat superior cervical ganglion to neuronal or nonneuronal fates. Neuron 6:741-752.

Hinds JW, Ruffett TL (1971) Cell proliferation in the neural tube: an electron microscopic and Golgi analysis in the mouse cerebral vesicle. Z Zellforsch 115:226-264.

Holt CE, Bertsch TW, Ellis HM, Harris WA (1988) Cellular determination in the Xenopus retina is independent of lineage and birthdate. Neuron 1:15-26.

Jones EG, Powell TPS (1970) Electron microscopy of the somatic sensory cortex of the cat. I. Cell types and synaptic organization. Philos Trans R Soc Lond [Biol] 257:1-11.

LeVine SM, Goldman JE (1988) Embryonic divergence of oligodendrocyte and astrocyte lineages in developing rat cerebrum. $J$ Neurosci 8:3992-4006.

Levitt P, Cooper ML, Rakic P (1981) Coexistence of neuronal and glial precursor cells in the cerebral ventricular zone of the fetal monkey: an ultrastructural immunoperoxidase analysis. J Neurosci 1:2739 .

Levitt P, Cooper ML, Rakic P (1983) Early divergence and changing proportions of neuronal and glial precursor cells in the primate cerebral ventricular zone. Dev Biol 96:472-484.

Luskin MB, Pearlman AL, Sanes JR (1988) Cell lineage in the cerebral cortex of the mouse studied in vivo and in vitro with a recombinant retrovirus. Neuron 1:635-647.

McConnell SK (1988) Development and decision-making in the mammalian cerebral cortex. Brain Res Rev 13:1-23.

McConnell SK (1991) The generation of neuronal diversity in the central nervous system. Annu Rev Neurosci 14:269-300.

McConnell SK, Kaznowski CE (1991) Cell cycle dependence of laminar determination in developing neocortex. Science 254:282-285.

McDermott, KW, Breding E, Luskin MB (1991) Clonal analysis of gliogenesis in the neonatal rat cerebral cortcx. Soc Neurosci Abstr 17: 733.

Nakatsuji N, Kadokawa Y, Suemori H (1991) Radial columnar patches in the chimeric cerebral cortex visualized by use of mouse embryonic stem cells expressing $\beta$-galactosidase. Dev Growth Differ 33: 571-578.

Nolan GP, Fiering S, Nicolas J-F, Herzenberg LA (1988) Fluorescenceactivated cell analysis and sorting of viable mammalian cells based on $\beta$-D-galactosidase activity after transduction for Escherichia coli lac Z. Proc Natl Acad Sci USA 85:2603-2607.

Parnavelas JG, Sullivan K, Lieberman AR, Webster KE (1977) Neurons and their synaptic organization in the visual cortex of the rat. Electron microscopy of Golgi preparations. Cell Tissue Res 183:499517.

Parnavelas JG, Luder R, Pollard SG, Sullivan K, Lieberman AR (1983) A qualitative and quantitative ultrastructural study of glial cells in the developing visual cortex of the rat. Philos Trans R Soc Lond [Biol] 301:55-84.

Parnavelas JG, Dinopoulos A, Davies SW (1989) The central visual pathways. In: Handbook of chemical neuroanatomy, $\mathrm{V}_{\mathrm{ol}} 7$, Integrated 
systems of the CNS, Pt II (Björklund A, Hökfelt T, Swanson LW, eds), pp 1-164. Amsterdam: Elsevier.

Parnavelas JG, Barfield JA, Franke E, Luskin MB (1991) Separate progenitor cells give rise to pyramidal and nonpyramidal neurons in the rat telencephalon. Cereb Cortex 1:463-468.

Peters A (1985) The visual cortex of the rat. In: Cerebral cortex, Vol 3, Visual cortex (Peters A, Jones EG, eds), pp 19-80. New York: Plenum.

Peters A, Palay SL, Webster F (1976) The fine structure of the nervous system: the neurons and supporting cells. Philadelphia: Saunders.

Price J, Thurlow L (1988) Cell lineage in the rat cerebral cortex: a study using retroviral-mediated gene transfer. Development 104:473482

Price I, Turner D, Cepko C (1987) Lineage analysis in the vertebrate nervous system by retrovirus-mediated gene transfer. Proc Natl Acad Sci USA 84:156-160.

Raedler E, Raedler A (1978) Autoradiographic study of early neurogenesis in rat cerebral cortex. Anat Embryol (Berl) 154:267-312.

Raff MC (1989) Glial cell diversification in the rat optic nerve. Science 243:1450-1455.

Rakic P (1981) Neuronal-glial interaction during brain development. Trends Neurosci 4:184-187.

Rakic P (1988) Specification of cerebral cortical areas. Science 241: 170-176.

Sanes JR, Rubenstein JLR, Nicolas J-F (1986) Use of a recombinant retrovirus to study post-implantation cell lineage in mouse embryos. EMBO J 5:3133-3142.

Sauer FC (1935) Mitosis in the neural tube. J Comp Neurol 62:377405.
Skoff RP (1980) Neuroglia: a reevaluation of their origin and development. Pathol Res Pract 168:279-300.

Skoff RP, Knapp PE (1991) Division of astroblasts and oligodendroblasts in postnatal rodent brain: evidence for separate astrocyte and oligodendrocyte lineages. Glia 4:165-174.

Snedecor GW, Cochran WG (1980) Statistical methods, 7th ed. Ames, IA: Iowa State UP.

Temple S (1989) Division and differentiation of isolated CNS blast cells in microculture. Nature 340:471-473.

Turner DL, Cepko CL (1987) A common progenitor for neurons and glia persists in rat retina late in development. Nature 328:131-136.

Vaughan DW (1984) The structure of neuroglial cells. In: Cerebral cortex, Vol 2 (Jones EG, Peters A, eds), pp 285-329. New York: Plenum.

Vaysse PJ-J, Goldman JE (1990) A clonal analysis of glial lineages in neonatal forebrain development in vitro. Neuron 5:227-235.

Walsh C, Cepko CL (1988) Clonally related cortical cells show several migration patterns. Science 241:1342-1345.

Walsh C, Cepko CL (1992) Widespread dispersion of neuronal clones across functional regions of the cerebral cortex. Science 255:434-440.

Wetts R, Fraser SE (1988) Multipotent precursors can give rise to all major cell types of the frog retina. Science 239:1142-1145.

Williams BP, Read J, Price J (1991) The generation of neurons and oligodendrocytes from a common precursor cell. Neuron 7:685-693.

Zilles K (1985) The cortex of the rat-a stereotaxic atlas. Berlin: Springer. 